\title{
A digital-based integrated methodology for the preventive conservation of cultural heritage: the experience of HeritageCare project
}

\author{
M.G. Masciotta ${ }^{\text {a* }}$, M.J. Morais ${ }^{\mathrm{a}}$, L.F. Ramos ${ }^{\mathrm{a}}$, D.V. Oliveira ${ }^{\mathrm{a}}$, L. J. Sanchez- \\ Aparicio $^{\mathrm{b}}$ and D. Gonzalez-Aguilera ${ }^{\mathrm{b}}$ \\ aISISE \& IB-S, University of Minho, Department of Civil Engineering, Guimarães, \\ Portugal
}

${ }^{b}$ High Polytechnic School of Ávila, University of Salamanca, Department of Cartographic and Land Engineering, Avila, Spain

*mg.masciotta@gmail.com

\begin{abstract}
A sustainable conservation strategy for cultural heritage protection is not feasible without a systematic documentation, registration and management of the information. The adoption of integrated inspection protocols and regular tracking processes, based on standardized procedures and uniform criteria, are the basis to successfully replace actual curative strategies with proactive conservation approaches. The opportunities brought by the digital tools can offer tremendous advantages in this regard. This paper explores the leading role that digitization is assuming in the context of heritage conservation through the experience of the HeritageCare project - Monitoring and preventive conservation of historic and cultural heritage" (SOE1/P5/P0258). The project has developed a digital-based integrated methodology aimed at providing enhanced tools and services to properly document cultural heritage buildings and engage directly owners in the conservation process of their legacy. The structured digital workflow on which the HeritageCare protocol relies is described in detail, encompassing different levels of information. Finally, the full application of the protocol is presented with reference to one of the most emblematic case studies of the project, the Ducal Palace of Guimarães, Portugal.
\end{abstract}

Keywords: integrated documentation protocol, cultural heritage, preventive conservation, digital tools, standardized inspection procedure, enhanced management 
“This paper can be found at https://doi.org/10.1080/15583058.2019.1668985"

\section{Introduction}

The implementation of a preventive conservation approach for Cultural Heritage $(\mathrm{CH})$ buildings entails several challenges. Points of concern are not just the physical objects per se, but also the multiple layered heritage values existing beyond them. Preventive conservation approaches are gaining attention as opposed to traditional strategies of curative conservation, in the attempt to systematize inspections and monitoring routines to address directly the causes of damage and minimize deterioration processes, thereby avoiding belated actions that often do not result in the removal of causative factors, but instead lead to a reactive pattern of treatments and overpriced interventions (Matulionis, 1991).

In order to facilitate monitoring activities and keep track of the conservation status of the cultural heritage, standardized and integrated documentation protocols are crucial to support decision-making processes for preventive conservation purposes, provided that accessibility and longevity of the information therein contained are guaranteed. The new opportunities brought by digital tools can be of great help in this regard. Indeed, one of the major benefits of the digital revolution is that information can be stored, manipulated, shared and transferred almost instantaneously from virtually anywhere in the world.

Although an increasing number of countries are supporting open cultural heritage data and promoting its reuse, systematic digital documentation workflows for preventive conservation and management of cultural heritage are still lacking. Without a systematic data collection and registration, a sustainable conservation strategy for cultural heritage protection is not feasible. To meet this challenge, the European project "HeritageCare Monitoring and preventive conservation of historic and cultural heritage" (SOE1/P5/P0258) has developed a series of standardized and integrated documentation protocols for assessing the conservation status of built cultural heritage over time, with 
“This paper can be found at https://doi.org/10.1080/15583058.2019.1668985"

tremendous advantages in terms of data collection and classification, systematic reporting, information digitization, comparative condition assessment over years and decision-making support in the short, medium and long term.

The present paper aims to present the HeritageCare experience towards the implementation of a multi-level integrated inspection protocol for the preventive conservation and management of built cultural heritage, rooted in the digitization of all heritage-related information. It aims at providing enhanced tools and services to properly document cultural heritage buildings and make them widely accessible to people, regardless of their location and financial status, thus engaging directly the society in the conservation process of its legacy. This protocol is intended to assist the decision-making process and to become a key tool for a sustainable conservation policy.

Dedicated web-based and mobile applications combining flexibility and easy access have been designed in accordance with the protocol of inspection defined during the project, enabling to keep track of the conservation status of the inspected buildings over time and to notify interested parties in case of alarming symptoms. Besides, advanced geomatic techniques have been leveraged to generate high-resolution virtual replicas of the inspected historic buildings for the accurate mapping and diagnosis of existing damages so as to obtain value-added data sources for the identification of affected areas and for the extraction of reference information for post-event analysis.

Lastly, 3D models of the inspected buildings have been created in Heritage Building Information Modelling (HBIM) environment, allowing to easily share, visualize and update all meaningful information about their conservation status and contributing to streamline their management process, while feeding an untethered device with a dedicated app conceived to offer an immersive and interactive mixed reality experience of the real-word heritage. 
“This paper can be found at https://doi.org/10.1080/15583058.2019.1668985"

An overview of the research context framing the origin of the project is provided in Section 2, with focus on the realities of the three Southwestern European countries that compose the project Consortium. After a brief summary of the development phases of the HeritageCare methodological approach for preventive conservation of historic and cultural heritage, the protocol for integrated documentation and management is detailed in Section 3. Thereafter, Section 4 presents the application of the methodology to one of the most representative case studies of the project, i.e. the Ducal Palace of Guimarães in Northern Portugal. Section 5 discusses the added value of the HeritageCare protocol as well as the benefits deriving from its implementation. Finally, Section 6 concludes the work.

\section{The HeritageCare system for preventive conservation}

\subsection{Research context}

The Southwestern Europe, hereinafter referred to as Sudoe, features an extremely rich natural and cultural heritage that needs to be protected and exploited in a sustainable manner. This can be pursued through the development of integrated conservation strategies and efficient management plans that can contribute to preserve and enhance both the tangible and intangible values associated with this legacy. Indeed, protecting the environment and promoting the efficient use of resources are the main objectives of the fifth priority axis launched by the European Commission within the Interreg Sudoe transnational cooperation Programme (www.interreg-sudoe.eu).

The cultural identity of the Sudoe space is deeply reflected in the constructive, material, morphological and typological characteristics of the numerous heritage buildings spread all over its territory. Focusing on three Sudoe countries with comparable cultural approaches, namely Portugal, Spain and Southwestern France, it is possible to identify 
basic common principles for cultural heritage preservation in line with the UNESCO recommendations (UNESCO, 1954, 1970, 1972, 2001, 2003, 2005). Nevertheless, in each of these countries, the standards and codes related to the protection, conservation and control of interventions on built cultural heritage have matured in distinct temporal and spatial contexts, and as a result of particular historic events, thereby giving place to different actuation criteria and management strategies (Ornelas, 2016). In Portugal, for instance, laws and codes dealing with the protection of built cultural heritage exist at both national and municipal levels (e.g. Regime de proteção e valorização do património cultural, Procedimento de classificação dos bens imóveis de interesse cultural, Regime jurídico da urbanização e edificação). However, such standards are mainly focused on individual immovable assets and present diffuse and disperse criteria, lacking any concern for the systematic documentation and management of the entire historic ensemble and for the definition of methodical criteria of intervention (Ornelas, 2016; Ferraz, 2016).

In Spain, despite the existence of a national law (Ley del Património Histórico Español, 1985) and a unique technical building code (Código Técnico de la Edificación - CTE), no uniform criteria and tools are defined at national level for the protection and conservation of built cultural heritage, thus each autonomous community establishes its own standards and procedures to categorize and act on historic buildings and assets (Ornelas, 2016; HeritageCare, 2017-a).

On the contrary, in France there is a strong coordination between the Ministry of Culture and the Regional Directorates for Cultural Affairs (DRAC) in matters concerning the protection of historic monuments as well as the authorization and control of conservation works. The aim is to ensure full coherence between the activities undertaken on heritage buildings and the preservation policies set in the national laws and codes (e.g. Livre Sixième $d u$ Code du Patrimoine); only qualified professionals belonging to specific 
“This paper can be found at https://doi.org/10.1080/15583058.2019.1668985"

hierarchical bodies, i.e. Architectes em chef des Monuments Historiques, Architects du Patrimoine, Architectes des Bâtiments de France, can be in charge of these activities. However, France's conservation system is not widely applicable, also because its main concern is focused on classified historic buildings and monuments, leaving aside a great deal of heritage constructions.

Statistically speaking, Portugal, Spain and Southwestern France acknowledge more than 31.000 classified buildings with historic and cultural value spread over an area of about $800.000 \mathrm{~km}^{2}$ (Figure 1) with a population of nearly 77 million inhabitants, which results into around 400 listed buildings per million inhabitants. Yet, the exact number of nonlisted buildings - which are indeed the majority - is unknown.

Despite the existence of national or regional institutions designated to the preventive conservation of built cultural heritage in the Sudoe regions, no policy exists for the systematic documentation, monitoring and management of its conservation state. Public money is not channelled into the creation of proactive conservation habits rooted in a solid culture of maintenance, thus the scarcity of financial resources (national funding is mostly addressed to listed buildings) combined with the lack of knowledge about proper preventive practices hinder owners from undertaking suitable conservation actions on their buildings in a timely way. The absence of regular preventive measures aimed at minimizing damage and deterioration processes ends in reactive patterns of intermittent and expensive interventions carried out only when the conservation status of the heritage is seriously impaired. This also reveals that the society is not fully aware of the benefits associated with regular inspections and preventive conservation actions, hence a paradigm shift is necessary to invert this trend.

One of the current major challenges in the implementation of a systematic strategy for preventive conservation of cultural heritage in Southwestern Europe is the dual demand 
“This paper can be found at https://doi.org/10.1080/15583058.2019.1668985"

for standardized inspection and monitoring procedures at an affordable cost but tailored to the conservation needs of each single building as well as to the owners' requirements. It follows that the integration, storage and management of the multiple data collected through the inspections become essential to guarantee a reliable database of information for effectively tracking the conservation status of heritage buildings over time according to a proactive perspective.

In this framework, the European project HeritageCare - Monitoring and preventive conservation of historic and cultural heritage is paving the way for implementing a new methodology for heritage preventive conservation in Portugal, Spain and Southwestern France. Among the different objectives, the project aims to make available to the society an affordable service for the systematic inspection, monitoring, conservation and management of built cultural heritage, whether listed or not, based on the use of a flexible inspection protocol for proper data collection and classification, as well as the creation of virtual and digital models for easy information integration and user-wide accessibility to primary conservation data.

Thanks to the fruitful collaboration of eight beneficiary partners and eleven associated partners from the three Sudoe countries involved (Portugal, Spain and Southwestern France), the HeritageCare project, coordinated by the University of Minho, succeeded in achieving all envisaged scientific and technical goals, including the creation of a nonprofit entity in each of the countries able to carry on the HeritageCare mission.

\subsection{The HeritageCare methodological approach}

The HeritageCare methodology for preventive conservation was developed in four main phases (Figure 2). The first phase was devoted to a literature survey about existing preventive conservation approaches and documentation protocols in the fields of built 
and movable cultural heritage, aiming to get a deeper insight into the methods and tools available. Online questionnaires were sent to owners and managers of various heritage buildings located in the Sudoe space to understand the state of conservation of their properties, comprehend the major problems experienced by the buildings and perceive the difficulties faced to carry out maintenance activities. The scope of this first phase was to gather as much information as possible to assess strengths and weaknesses of current conservation systems and to characterize the Sudoe territory and relevant cultural heritage in order to better target stakeholders' demands and requirements during the subsequent development phases. The survey revealed the absence of uniform and standardized methods for the documentation and management of cultural heritage, highlighting the need for systematic classification criteria and optimized workflows, in harmony with existing standards, but flexible enough to be applicable to the great variety of existing heritage structural typologies and construction systems.

As a first step towards the definition of a common cataloguing framework, historic buildings were grouped into 9 typologies, while movable and integrated heritage assets were organized into 12 categories (Figure 3-a). In what concerns the damages, a hierarchical taxonomic classification was adopted on the basis of shared characteristics, distinguishing among 7 damage classes further divided into sub-classes and sub-subclasses (Figure 3-b), for a total of 87 types of damages for buildings and 79 for assets, organized in the form of a Damage Atlas. Translated into 4 languages (English, Portuguese, Spanish and French), such a supporting tool represents a fundamental part of the HeritageCare database, providing valuable reference information during inspection activities for the characterization and preliminary diagnosis of the observed pathologies as well as for the identification of suitable mitigation actions to minimize the damage consequences. Moreover, with the objective of creating a common representation 
“This paper can be found at https://doi.org/10.1080/15583058.2019.1668985"

language among HeritageCare inspectors, a damage code with established patterns was defined for all the damage types described in the Atlas.

A significant step forward in terms of information cataloguing and modelling was made through the identification of $\mathrm{CH}$ buildings ontologies and the proposal of structured data templates for historic objects in order to enrich HBIM libraries. Although the increasing relevance that the Historic Building Information Modelling is assuming in the context of AECO industry, the BIM methodology itself and related software are mainly oriented to new constructions. Hence, aspects such as level of detail (LoD), level of information (LoI), modelling of tolerances and damages still represent important challenges in HBIM environment and existing protocols have not yet found a large consensus (Azenha, 2018). With the aim of fully leveraging BIM potential for maintenance and preventive conservation of heritage buildings, specific data structures for historic construction elements were proposed (Alarcón, 2018). In what concerns the LoD of heritage objects, as a general rule, the metric value was considered more important than the morphological value: most of element features are represented, with a proper differentiation of materials, but global dimensions can have $\pm 5 \mathrm{~cm}$ tolerance; ornamental details are not modelled; curved elements like arches, vaults, and domes, are represented by their ideal geometry. As for the LoI, six categories of parameters encompassing not only geometrical and construction data, but also other types of data crucial for $\mathrm{CH}$ management purposes (Table 2), were defined (Alarcón, 2018). Regarding the description of damage information, a patch-type object representation was proposed except for the deformations, which are not described geometrically but in terms of embedded parameters. The LoI of the patch-type damage objects was established based on the information provided in the HeritageCare Damage Atlas, like class, main features, condition grade, symptoms and causes, incorporating also inspection data and control parameters to track the damage evolution. 
“This paper can be found at https://doi.org/10.1080/15583058.2019.1668985"

Finally, all graphical and non-graphical contents of the HBIM objects created according to the afore-mentioned criteria were translated into an open exchange format, i.e. the IFC file, through an importing, mapping and conversion process.

The second phase of the project was focused on the definition of the integrated methodology for preventive conservation of built cultural heritage by developing standardized data collection protocols, flexible inspection procedures, and establishing uniform criteria for assessing the conservation state of the inspected heritage buildings and assets (HeritageCare, 2017-b). In line with the European standards in the field of cultural heritage conservation (EN 2011, 2012), such a methodology aims to help owners and managers of heritage buildings prevent - or at least minimize - the damages affecting their properties through a system of services organised in three complementary levels (Figure 4), i.e. Service Level 1 (SL1), Service Level 2 (SL2) and Service Level 3 (SL3). These levels reflect the quantity and complexity of the information that is progressively collected on the built heritage to efficiently document its current state of conservation (encompassing historical, geographical, architectural, structural and material aspects), as well as the increasing sophistication of the tools that are used across the three levels for capturing, integrating, visualizing and managing the multiple and heterogeneous information gathered through the proposed inspection protocol.

SL1 (StandardCare) aims at providing a rapid condition screening of the heritage asset by identifying its main pathologies and deterioration mechanisms, thus delivering essential information for the primary conservation needs and ordinary maintenance of the building. SL2 (PlusCare) offers a more extended knowledge of the heritage ensemble by integrating SL1 information with accurate geometric surveys, detailed assets inspections, damage mapping, in-depth historic documentation and monitoring of meaningful parameters, thus allowing to better address the specific conservation needs of the heritage 
“This paper can be found at https://doi.org/10.1080/15583058.2019.1668985"

building along with its integrated and movable assets. Finally, SL3 (TotalCare) integrates and manipulates all data collected from previous service levels through an intelligent HBIM-based digital model that enables not only to visualize the physical and functional attributes of a building, but also to quickly identify major problems and explore potential issues associated with the conservation/management process of the construction, allowing a priority-based scheduling of maintenance actions and supporting decisionmaking procedures. The selection of the service level depends on the building conservation needs and owner's requirements/financial availability. As a general rule, the higher the complexity of the heritage building, the higher the service level recommended. The third phase was dedicated to the development of the HeritageCare transversal tools, namely: (1) a capable and structured database for information catalogue and data storage; (2) a web application running on a remote server for back-office access, upload, management and update of the stored information; and (3) a mobile application running on a tablet for offline information upload and retrieval during inspections. The major goal of this phase was to create an interoperable web platform for optimal information organization and management, widely accessible by experts (inspectors) as well as by public entities and non-expert users (owners and stakeholders in general) upon successful authentication and authorization.

The fourth and last phase of the project was committed to the implementation of the HeritageCare methodology in the three Sudoe countries. To this end, a minimum number of sixty case studies were chosen across Portugal, Spain and Southwestern France based on specific criteria and trying to encompass representative building typologies in each region at different conservation stages. The inspection protocol for SL1 was applied to all selected case studies, at least twenty heritage buildings per country. Among them, fifteen buildings - five per country - were chosen for implementing the HeritageCare 
inspection protocol up to SL2; finally, out of these fifteen buildings, three were picked to apply the full inspection protocol up to the last service level, resulting into one SL3 case study per country. For the sake of illustration, the results from the full application of the HeritageCare protocol are presented in Section 4 with reference to one of the most emblematic Portuguese case studies.

\section{HeritageCare protocol for integrated documentation and management}

A sustainable and proactive approach to the preventive conservation of built cultural heritage must be rooted in the systematic documentation and assessment of its conservation status through a consistent protocol for inspection, diagnosis and monitoring. This should provide guidance on the most appropriate maintenance and preventive conservation actions that can be undertaken over time to avoid that minor problems turn into future damages. Since each heritage building is unique and can present diverse pathologies, the organization, ranking and strategic planning of all the stages of the inspection process are crucial for the identification of case-specific preventive measures.

To face this challenge, HeritageCare has developed a structured three-level inspection protocol to guide the processes of documentation, digitization and management of cultural heritage, trying to establish common representation and condition assessment criteria across diverse building types without disregarding the different levels of detail, peculiarities and conservation requirements that each building may feature. Per each service level (SL1 - StandardCare, SL2 - PlusCare, SL3 - TotalCare), the protocol provides a repeatable workflow, meaning a systematic sequence of orchestrated steps for consistent data collection, classification and reporting before, during and after onsite 
inspections. The application of such a protocol shall guarantee a uniform metric between inspections tailored to diverse necessities.

\section{StandardCare Protocol (SL1)}

The StandardCare protocol entails three main steps: (1) Building ID and management information; (2) State of conservation assessment; (3) Data verification and information restitution. Each step includes specific data categories and activities which are deemed essential to gather primary information about the building's identity and conservation state (Figure 5).

Building ID and management information comprise all data regarding the general documentation of the 'object', such as name, category, classification, property, time of construction, original and current functions, contextualization, spatial localization, maps and relevant surveys, important historical information, architectural features, construction system, principal building materials, previous interventions and/or maintenance actions, number of integrated and movable assets of cultural interest.

State of conservation assessment incorporates all data concerning the documentation and classification of the building condition. To guarantee a common metric for condition survey, inspectors' fieldwork is supported by a mobile app running on a tablet with a standardized checklist of items and sub-items to inspect (Figure 6-a). Per each sub-item, the main damages and deterioration processes are identified, and their degree of severity is assessed by a 'damage rating system' that associates a condition index and a risk index to each of the observed damages. To avoid huge differences in the classification, a 4point scale from 0 to 3 is used for both condition and risk assessment (Table 1). The grade of each sub-item is computed by taking into account the type and extent of existing damages and is weighed upon a percentage factor depending on the importance that the sub-item plays as compared to the other sub-items of the same category. The final grade 
“This paper can be found at https://doi.org/10.1080/15583058.2019.1668985"

of each item is rounded up to the condition grade of the most damaged sub-item. Lastly, an overall condition classification is provided by averaging the grades scored by the inspected items organised into four macro-categories (Figure 6-b). This procedure helps ranking the building condition in a nearly objective way and assists in prioritizing the necessary maintenance and preventive conservation actions.

Data verification and information restitution focus on the offsite processes of completion, amendment and validation of the information collected onsite as well as on the elaboration of damage maps to visually support the inspection outcome. Per each documented damage, causes, consequences and recommendations on possible mitigation and preventive measures are also provided. Finally, upon successful finalization and storage of the inspection process, a condition report is automatically generated from the HeritageCare platform. This document represents the main output of the StandardCare protocol and is intended to deliver to the building owner essential information about the overall condition of its property along with advices and recommendations about the main actions to undertake in the short, medium and long term to avoid further decay and prevent future damage.

\section{PlusCare Protocol (SL2)}

The PlusCare protocol entails the three main steps of the StandardCare protocol plus five steps accounting for further data categories and information, aimed to enrich and extend the SL1 documentation about the heritage ensemble: (1) Assets ID and condition survey; (2) 3D documentation; (3) Monitoring data; (4) Additional records; (5) Data processing and information integration (Figure 7).

Assets ID and condition survey include all data regarding the general documentation of the main integrated and movable assets found in the inspected building (e.g. name, category, classification, property, period of crafting/manufacturing, main geometrical 
features, materials, location) as well as the data concerning the documentation and classification of their conservation state. Per each asset, the same 4-point rating system used for SL1 inspections is employed to assess the degree of severity of the observed damages and deterioration processes, also based on their extent. The final grade is then computed from the round weighted sum of the single grades assigned to the different damages affecting that asset, allowing to prioritize the conservation measures depending on the scored condition and risk indexes.

3D data documentation relates to the creation of high-resolution 3D digital models of the inspected buildings for accurate geometrical representation, quality inspection and damage mapping. Image-based methods, such as terrestrial or aerial photogrammetry, or range-based methods, like static or dynamic laser scanning, can be used for this purpose. It is noted that the choice of the most appropriate 3D recording strategy depends on the complexity and size of the cultural heritage 'object' to digitalize (Table 3). The collection of panoramic photos with $360^{\circ}$ fields of view about the heritage ensemble complements this documentation, allowing to generate immersive virtual environments in which all the information is linked spatially.

Monitoring data comprises all key information gathered from the periodic or continuous tracking of physical, mechanical and environmental parameters or state indicators (e.g. inbound or outbound transit, crack width, tilting, luminosity, temperature and humidity, among others) that can help better analyse the structural behaviour and evaluate the future conservation needs of the inspected building and assets, allowing to tailor ad hoc preventive measures. In order to adequately select monitoring parameters that can provide meaningful information about the observed phenomena, the outcome of SL1 condition survey is crucial. 
“This paper can be found at https://doi.org/10.1080/15583058.2019.1668985"

Additional records encompass all supplementary data and information that can contribute to increase the level of knowledge about the heritage buildings/assets and their conservation state, including detailed historic information, results from previous testing campaigns, structural interventions or restoration reports, photos, drawings, and the like. Data processing and information integration focus on the back-office work necessary to convert the captured data into final products. Digital replicas of cultural heritage are created and stored into an optimised Geographical Information System (GIS), linked to the HeritageCare database. All significant information regarding the conservation state of both buildings and assets are integrated into this system - e.g. SL1 condition report, point clouds, assets information, monitoring data, additional records - together with their relevant input imagery. The result is a user-friendly interface composed by $360^{\circ}$ spherical panoramas across which building owners can virtually navigate and access the stored information just by clicking on pre-defined hotspots (e.g. damage hotspot, asset hotspot, sensor hotspot, etc.). These virtual tours represent the main outputs of the PlusCare protocol. Besides being extremely appealing, such products offer owners an enhanced and immersive knowledge experience of their structures, where visual insights into the geometrical and conservation aspects of their buildings are provided on screen together with real-time updates of the monitored parameters. To foster an easy interpretation of the monitored quantities by non-expert users, only essential data are shown by adopting a 3-colour grading system that automatically rates the recorded values as good, acceptable or bad. This way, owners are given a handy tool reflecting the conservation state of their buildings that can provide assistance in their daily maintenance routine and act as reference data source for future condition assessment. 
“This paper can be found at https://doi.org/10.1080/15583058.2019.1668985"

\section{TotalCare Protocol (SL3)}

In the framework of increasing complexity and sophistication with increasing levels, the TotalCare protocol enriches the PlusCare protocols with four extra steps aimed at developing interoperable 3D digital models of the cultural heritage where all relevant documentation and information collected across the previous service levels are integrated and managed. These additional three steps include: (1) Object definition; (2) Building information modelling; (3) Data exportation and storage; (4) $\mathrm{CH}$ documentation enhancement (Figure 8).

Object definition concerns the creation/selection of a library of HBIM families suitable for modelling the inspected heritage building. Indeed, each BIM model is an assembly of "objects" made with an architecture software. Each object is the digital description of a certain model element, carrying parametric attributes. This means that each object needs to be defined only once and can be placed in the model in multiple locations as required. Moreover, if the object is changed, these changes will appear throughout the model.

Building information modelling refers to the allocation of HBIM objects in the space and in specific relations to other objects. Based on the information collected in the previous service levels, high accuracy can be achieved in this task. For instance, the point clouds captured in SL2 can be exploited to cross check quantitative information such as the geometry of the model; the historic documentation can be used to distinguish the construction phases of the building; the condition survey and damage maps can be utilized to represent and describe the existing structural and non-structural damages; the condition and risk ranking system can be employed to set minimum conservation requirements and maintenance levels; the monitoring data can be used to define acceptable condition ranges; and so forth. The result is an intelligent HBIM model populated with meaningful attributes that can be accessed, manipulated and updated by expert users, enabling a streamlined management of the conservation process of the built cultural heritage over 
time and supporting informed decision-making procedures. Additionally, this model can be exploited for structural analysis purposes upon an adequate exportation and conversion process.

The third step involves the exportation and storage of this enriched 3D digital model which is the main output of the TotalCare protocol - into the HeritageCare platform. HBIM models can be created with different software but, to facilitate interoperability and to guarantee data sharing and exchanging across different software applications, they are exported into neutral, non-proprietary data formats, i.e. the IFC files. These files are then uploaded to the HeritageCare platform along with their original counterparts, which can be easily opened through free and open source BIM visualizers.

Finally, $\mathrm{CH}$ documentation enhancement relates to the interactive Mixed-Reality (MR) experience of the real-word heritage that is obtained by visualizing BIM-generated digital information together with the physical objects. First the IFC file of the model is converted

into a usable 3D model, then all non-geometric information is extracted/parsed; finally, a GUID table is used to hook this information to the right parametric objects and contextualize data correctly. The result is a MR inspection tool (HoloLens) through which HeritageCare inspectors can flawlessly interact with the real building, access stored information from previous inspections, take measurements with a simple gesture and detect cracks based on pattern recognition algorithms. The primary aim of the HoloLens application is to support inspection activities and informed decisions for conservation purposes, so information quality comes first.

\section{Case-study application: the Ducal Palace of Guimarães}

As mentioned before, during the project the HeritageCare protocols and transversal tools have been successfully tested across a great number of heritage buildings among Portugal, 
Spain and Southwestern France. As an example, this section summarizes the application of the HeritageCare protocol to one of the Portuguese case studies, the Ducal Palace of Guimarães. The building features a quadrilateral layout with protruding bodies on the rear façade and corners. It develops around a rectangular courtyard, surrounded by a two-story portico, occupying a ground area of about $3143 \mathrm{~m}^{2}$ (Figure 9). The thick bearing masonry walls are made of regular shaped granite stones and pierced by iron glazed windows, while chestnut wood is used for the timber roof supporting structures. The floors are supported by timber cladded concrete beams and covered with tiles. A complex system of hip roofs boasting 39 brick chimneys, each linked to its own fireplace with only four being original, crowns this noble construction. The Ducal Palace was built in the 15 th century by D. Alfonso (illegitimate son of the King João I and Inês Pires Esteves), first Duke of Bragança and eighth Count of Barcelos, on the occasion of his second wedding with D. Constança de Noronha. During the following centuries, owing to political and economic reasons, the palace was abandoned and fell into ruin. Starting from 1807 until 1935, the building was used as a military quarter, thereby suffering several alterations. The actual configuration of the palace is the result of a profound intervention of reconstruction that took place between 1937 and 1959 aimed at reintegrating the missing parts of the building and restoring its primitive unity. Elevated to national monument in 1910, the Ducal Palace hosts a museum inaugurated in 1959 and is one of the most visited monuments in Portugal.

Given the scale and complexity of the building, the TotalCare protocol was deemed as the most appropriate to fully assess its state of conservation and target the manager's requirements. After a documentary research to collect essential information about the building identity and plan the subsequent field work, a systematic inspection of the palace was carried out by an equipped team of HeritageCare inspectors making use of the mobile 
“This paper can be found at https://doi.org/10.1080/15583058.2019.1668985"

e-form developed within the project. HeritageCare inspections are usually performed by at least 2 professionals with complementary expertise. As for the present case study, the joint work of more inspectors was required to cover the entire building within a reasonable number of working hours.

Apart from the presence of biological growth, particularly lichens, on the stone battlement and roof tiles, the condition survey revealed problems of humidity due to water infiltrations through the roof covering, walls and opening frames, likely imputable to an insufficient slope of the roof drainage system and clogged gutters, loss of mortar between masonry units and lack of adequate waterproofing membranes in the windows, respectively. Ongoing stone disintegration phenomena originated from the use of limecement mortar in previous repointing works were also observed in the South-East façade. Moreover, structural superficial cracks worth of further diagnostic investigations were detected on the ground floor bearing walls perpendicular to the South-West façade.

Each damage was accurately documented and assessed according to the defined damage rating system. Thanks to the use of the mobile e-form (Figure 10), a real-time digitization of the entire inspection process was possible, being the app provided with synchronization options that allow the direct storage of the uploaded information into the HeritageCare database, with tremendous advantages in terms of data reporting time.

During the field work, targeted interviews were also made to the staff to get a better insight into the main problems of the building and to complement the visual inspection with information that could be hardly obtained otherwise.

Once back to office, data were further analysed and verified, and damages were mapped. Per each reported damage, the necessary maintenance and conservation actions to undertake in the short, medium and long term were specified. Based on the condition and risk grades scored by the inspected items, an overall evaluation about the conservation 
state of the building was established. Finally, a condensed inspection report was automatically produced (Figure 11) and made available to the manager of the Ducal Palace through a dedicated area within the HeritageCare platform. Only significant information about the building condition was provided, using a 4-colour grading system to highlight damage and relevant recommendations depending on their priority of intervention.

In order to achieve a more detailed knowledge of the Ducal Palace, the SL1 documentation was enriched and integrated with data concerning: the inventory and condition survey of the main integrated and movable assets; the accurate geometry of the palace; the monitoring of key parameters. In what concerns the assets, the Palace treasures hundreds of art pieces dating back to the 17th and 18th centuries, all featuring a good or fair conservation state, except for a few pieces, which were indeed object of closer inspections by the HeritageCare team. The damages and deterioration processes affecting these objects were identified and their degree of severity assessed according to the HeritageCare rating system. The information collected onsite was later uploaded to the platform by filling the relevant sections of the asset inspection forms.

To obtain high-resolution information about the geometry and onsite conditions of the palace, a laser scanner survey was carried out to digitally capture 3D geometric data as point clouds. Given the dimensions of the structure, the adoption of geomatic techniques offered remarkable advantages, allowing to collect significantly higher and more precise volumes of data in much less time. Considering the final aim of the survey, a Leica ScanStation P20 was used. This laser scanner is based on the Wave Form Digitizer principle which combines the time-of-flight and phase shift measurement technology to capture the data. Apart from that, this laser has a maximum range of $120 \mathrm{~m}$ and a maximum capture rate of 1.000 .000 points per second. Four full working days were 
necessary to scan both the interior and exterior of the building, excluding post-processing time. The result was a huge set of millions of points carrying accurate spatial information about the current state of the construction and acting as valuable reference data for future comparisons and analyses (Figure 12-a). In parallel, $360^{\circ}$ panoramic photos were taken both inside and outside the building and stored into the HeritageCare database for the subsequent integration of information. To this end, the Ricoh theta V camera was used. This camera is equipped with two fish-eye lenses that allow to capture the whole scene in a single shot, generating a $360^{\circ}$ image with 14 MPx of resolution (Figure 12-b).

With the aim of collecting more data to thoroughly evaluate the actual condition of the Ducal Palace and better address its future conservation needs, based on the outcome of the SL1 inspection, an advanced monitoring system (www.mhsproject.com; Chiriac, 2013) was installed in the South wing of the building to keep under control specific structural and environmental parameters. The type and location of sensors were chosen according to the features to be extracted and in conformity with the directions of the DRCN (Northern Regional Directorate of Culture), with the purpose of minimizing the visual impact of the sensors. The system is active since October 2018 and it is composed by:

- 12 temperature and relative humidity sensors (TH), of which 7 surface and 5 ambient sensors, plus 5 combined sensors measuring surface temperature, relative humidity and luminosity (THL). These sensors were installed to monitor the fluctuations of ambient parameters on the outer and inner sides of the South-West wall and rooms where major problems of humidity were observed;

- 3 xylophagous sensors (X) to detect the presence of xylophagous insects into the timber supporting structures of the main saloon's and chapel's roofs; 
“This paper can be found at https://doi.org/10.1080/15583058.2019.1668985"

- 1 carbon dioxide sensor $(\mathrm{G})$ to check hourly average values of $\mathrm{CO}_{2}$ inside the space;

- 2 biaxial clinometers (CL) to measure possible tilting mechanisms of the South-West wall;

- 1 meteo station (EM) to record outer air temperature, humidity, barometric pressure, wind direction and velocity, precipitations, rain duration, hail, solar radiation and carbon dioxide.

The sensors layout is schematized in Figure 13. To better follow daily and hourly variations of ambient parameters, values are sent to the central node every 15 minutes and updated every hour into the HeritageCare platform where all nodes were registered at the time of installation. By making use of the HeritageCare plugin for Pano2VR, SL1 and SL2 documentation (inspection report, damages, assets, point clouds, sensors) was integrated and georeferenced within the PlusCare system, and a virtual tour composed by sequential panoramic images with added information about the building condition was elaborated (Figure 14). Through this visual tool, the manager of the Palace is able to interactively navigate across its structure and access fundamental information about type and location of existing damage (with direct link to the Damage Atlas), assets condition, geometric details and spatial distribution of volumes, sensor position and real-time colour-based warnings of the monitored parameters in case of deviation from the acceptable limits.

Lastly, a BIM model of the Ducal Palace was built using Autodesk Revit. Apart from windows, doors, arches and columns, most of the model elements were created hereditarily based on the native families of the software and assigning them graphical and non-graphical attributes according to the data template structures established in the project framework (Alarcón, 2018). The hardest challenge consisted in modelling the 
inverted ship's hull and supporting structure of the timber roofs. Table 4 shows some of the surveyed elements in the Palace and the correspondent digital representation in Revit. The point clouds captured in SL2 were then exploited for the correct spatial and hierarchical allocation of the HBIM objects and to cross check the geometrical fidelity of the model. As an example, an isometric view of the BIM model is displayed in Figure 15 along with a sectioned perspective, showing the complexity of the timber roof structure as a whole. In order to streamline management procedures, the model was finally populated with all meaningful information collected across the different stages of the HeritageCare protocol about the conservation state of the building, including existing damage and monitoring system. The patch-type objects and relevant data template structures described in Section 2 were used for this purpose.

This enriched 3D model was finally exploited to feed the smart glass inspection app developed within the project. By wearing a pair of HoloLens, HeritageCare inspectors could visualize the BIM model of the palace on top of the real building, interacting flawlessly at the parametric object level and accessing all geometric and non-geometric information of these objects, including data from previous inspections for direct comparison. As a last step, both the Revit and correspondent IFC files were uploaded to the HeritageCare platform and made available to the Ducal Palace's manager through his dedicated area.

\section{Discussion}

Documentation and tracking processes, based on clear and uniform criteria, are the basis for protecting movable and built cultural heritage. At the same time, the collection of a huge amount of multiple data and heterogeneous information can reach such an extensive scale that major problems may arise in terms of classification, integration, management 
“This paper can be found at https://doi.org/10.1080/15583058.2019.1668985"

and access. The HeritageCare methodology and related transversal tools can have a tremendous impact on the systematization, analysis, comprehensive inclusion and tracking of the vast information originating from different inspection and diagnosis techniques, being the protocol rooted in standardized procedures and optimized workflows. The HeritageCare system allows to deal with a great variety of building typologies and is conceived to handle a growing amount of information. The co-existence of three inspection levels ensures the scalability and flexibility of the system according to the complexity and conservation needs of the building as well as to the owner/manager's requirements. All the information about the inspected constructions and assets is digitized, integrated and stored to create a reference database to facilitate monitoring activities and support condition-based maintenance actions. However, primary data concerning the buildings condition are made available to the respective owners (or managers) by logging into the database via a restricted access through the project website. In case of serious or urgent problems, the owner (manager) or responsible national authorities are alerted and advised to contact an expert either to perform in-depth diagnostic investigations or to plan a prompt intervention. Information about construction companies operating according to the best practices and with recognized experience is also provided. Indeed, the role of the HeritageCare inspectors lies at the upstream of the $\mathrm{CH}$ conservation flow, being aimed at addressing the causes of damages and minimizing deterioration processes in order to avoid invasive and expensive belated interventions. Understanding the real benefits associated with a proactive conservation approach will ultimately lead to both social and economic advantages. The HeritageCare protocol can become a key tool for a sustainable conservation strategy. Still, it will continue to be used, reviewed, updated and enhanced by the non-profit HeritageCare entities set up in the three partner Countries of the project. 


\section{Conclusions}

This paper presented the multi-level system for inspection, monitoring, preventive conservation and management of historic and cultural heritage, developed in the framework of the HeritageCare project (SOE1/P5/P0258). The proposed methodology relies on an integrated and flexible documentation protocol based on optimised digital workflows and widely applicable to the variety and peculiarities of existing heritage buildings and assets, either listed or not. The HeritageCare protocol provides with standardized inspection procedures, common documentation and classification criteria as well as unified rating systems for condition and risk assessment in order to allow a nearly objective recording of the data documenting the current state of conservation of cultural heritage. A web platform linked to a capable database and with established entries supports the HeritageCare protocol and data management, facilitating monitoring activities and guaranteeing accessibility and longevity of the stored information. Indeed, without a systematic data collection and registration, a sustainable conservation strategy for cultural heritage protection is not feasible.

Full details about this digital-based integrated methodology are given in the paper and its systematic application is demonstrated through the case study of the Ducal Palace of Guimarães, Portugal. It is shown that the protocol can be tailored to the building scale and conservation needs, offering case-specific outputs that provide owners/managers with valuable information about the conservation state of their heritage structures and act as supporting tools to guide them on the most appropriate maintenance and preventive conservation actions to undertake over time in order to avoid that minor problems turn into future damages. 
“This paper can be found at https://doi.org/10.1080/15583058.2019.1668985"

\section{Acknowledgments}

This work was carried out within the scope of the project HeritageCare (SOE1/P5/P0258), co-funded by the Interreg-Sudoe/FEDER program and included in the research activities of the ISISE Research Centre, also financed by FEDER funds through the Competitiveness Factors Operational Program - COMPETE and by national funds through FCT - Foundation for Science and Technology within the scope of the project POCI-01-0145-FEDER-007633.

The authors would like to express their gratitude to the Centre for Computer Graphics, Portuguese partner of the HeritageCare project, for the development of the database, web platform and mobile applications. The contribution of Dr. Miguel Azenha and Mr. Carlo Alarcon to the HBIM modelling is also greatly appreciated. The authors' thanks are extended to Santa Maria la Real Foundation, Spanish partner of the HeritageCare project, for the installation of the monitoring system in the Ducal Palace. Finally, the fifth author would like to thank the University of Salamanca for the program for human resources "Programa II: Contratos Postdoctorales".

\section{References}

Alarcón, C. 2018. Building information modelling in the context of structural preservation of historical monuments: methodological aspects and application to "Paço dos Duques". Master’s Thesis, University of Minho, Guimaraes, Portugal.

Azenha, M., M.G. Masciotta, G. Sousa, C. Alarcon, M.J. Morais, J. Sena-Cruz, D.V. Oliveira. 2018. Building Information Modelling (BIM) no contexto dos edifícios antigos. In: Conferência Internacional sobre Reabilitação de Estruturas Antigas de Alvenaria - CIRea2018, Lisbon, Portugal.

Chiriac, M., D. Basulto, E. López et al. 2013. The MHS system as an active tool for the 
“This paper can be found at https://doi.org/10.1080/15583058.2019.1668985"

preventive conservation of Cultural Heritage. In: Rogerio-Candelera M.A., Lazzari M., Cano E. (eds) Science and technology for the conservation of cultural heritage. CRC Press, pp. 383-386.

EN 15898:2011 Conservation of cultural property - Main general terms and definitions. EN 16095:2012 Conservation of cultural property - Condition recording for movable cultural heritage.

EN 16096:2012 Conservation of cultural property - Condition survey and report of built cultural heritage.

Ferraz, G.T., J. de Brito, V.P. de Freitas, and J. D. Silvestre. 2016. State-of-the-Art Review of Building Inspection Systems. Journal of Performance of Constructed Facilities. 30 (5).

HeritageCare, 2017-a. Survey of construction systems, type of damages and deterioration processes within the SUDOE ter-ritory. Unpublished document, HeritageCARE (Report of the Project Activity 1.1).

HeritageCare, 2017-b. General methodology for the preventive conservation of cultural heritage buildings. Unpublished document, HeritageCARE (Report of the Project Activity 1.2).

http://www.mhsproject.com

https://www.interreg-sudoe.eu

Matulionis, R.C. and J.C. Freitag (eds). 1991. Preventative Maintenance of Buildings. Van Nostrand Reinhold. New York, NY.

Ornelas, C., J.M. Guedes and I. Breda-Vázquez. 2016. Cultural built heritage and intervention criteria: A systematic analysis of building codes and legislation of Southern European countries. Journal of Cultural Heritage. 20: 725-732.

UNESCO. 1954. Convention for the Protection of Cultural Property in the Event of 
"This paper can be found at https://doi.org/10.1080/15583058.2019.1668985"

Armed Conflict with Regulations for the Execution of the Convention, United Nations

Educational, Scientific and Cultural Organization, Hague Convention.

UNESCO. 1970. Convention on the Means of Prohibiting and Preventing the Illicit Import, Export and Transfer of Ownership of Cultural Property, Paris Convention.

UNESCO. 1972. Convention concerning the Protection of the World Cultural and Natural

Heritage. United Nations Educational, Scientific and Cultural Organization, The General Conference of the UNESCO, Paris.

UNESCO. 2001. Convention of the Protection of Underwater Cultural Heritage. United Nations Educational, Scientific and Cultural Organization, The General Conference of the UNESCO, Paris.

UNESCO. 2003. Convention for the Safeguarding of the Intangible Cultural Heritage.

United Nations Educational, Scientific and Cultural Organization, The General Conference of the UNESCO, Paris.

UNESCO. 2005. Convention on the Protection and Promotion of the Diversity of Cultural Expressions. United Nations Educational, Scientific and Cultural Organization, The General Conference of the UNESCO, Paris. 
"This paper can be found at https://doi.org/10.1080/15583058.2019.1668985"

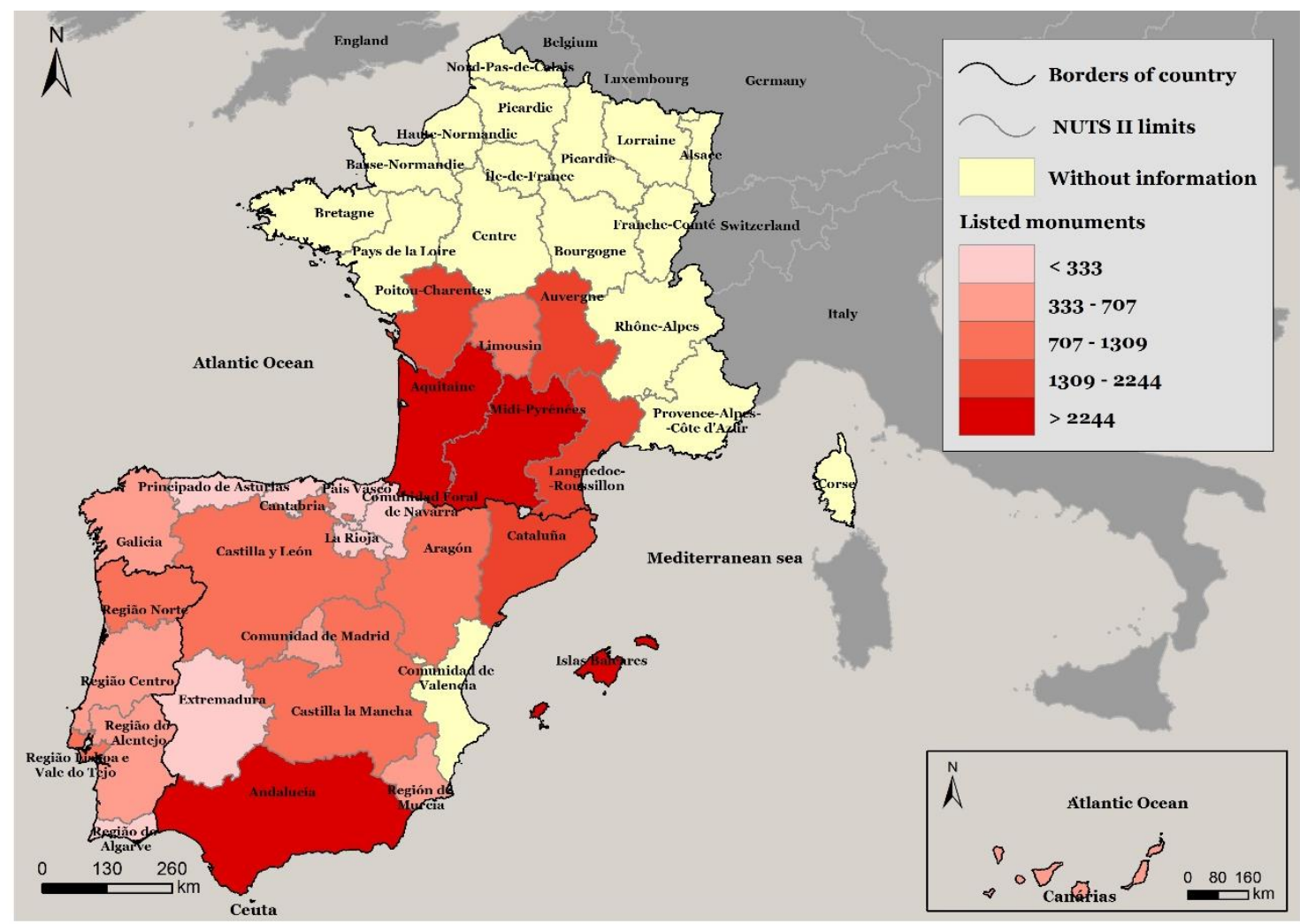

Figure 1. Distribution of heritage buildings in Southwestern Europe: total number of listed monuments by Region (HeritageCare, 2017-a). 


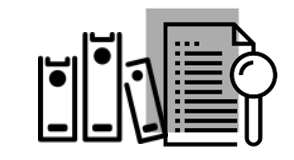

1. SURVEY \& CATALOGUING

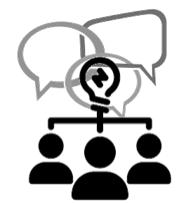

2. PROTOCOL DEFINITION

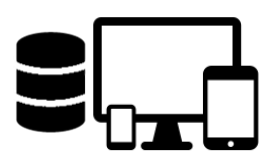

3. TOOLS DEVELOPMENT

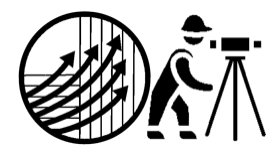

4. PROTOCOL IMPLEMENTATION

Figure 2. The four phases of the HeritageCare methodological approach. 


\section{Building Typologies (9)}

\section{Asset Categories (12)}

- Archaeology

- Civil architecture

- Religious architecture

- Military architecture

- Industrial architecture

- Garden architecture

- Funeral, commemorative or votive architecture

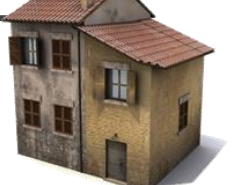

- Altar pieces

- Ceramics

- Furniture

- Jewellery

- Metal works

- Paintings

- Scientific instruments

- Sculptures

- Rural architecture

- Civil engineering structures

- Stained glasses

- Textiles

- Weapons

- Documentary \& bibliographic heritage
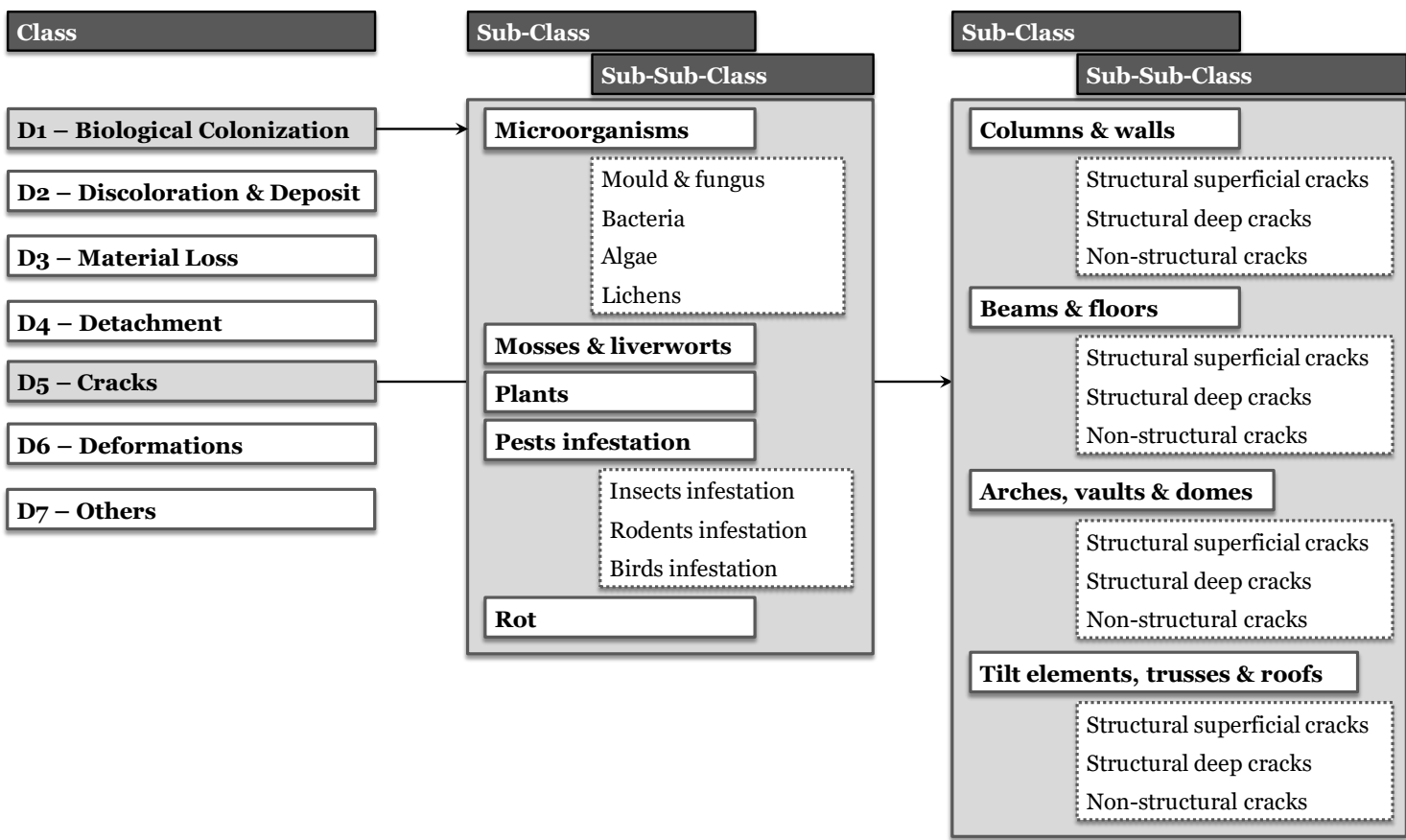

Figure 3. HeritageCare cataloguing framework: (a) buildings typologies and assets categories; (b) example of hierarchical classification of damages adopted in the Building Damage Atlas. 
Common 4D database/web platform

\section{Service Level 1}

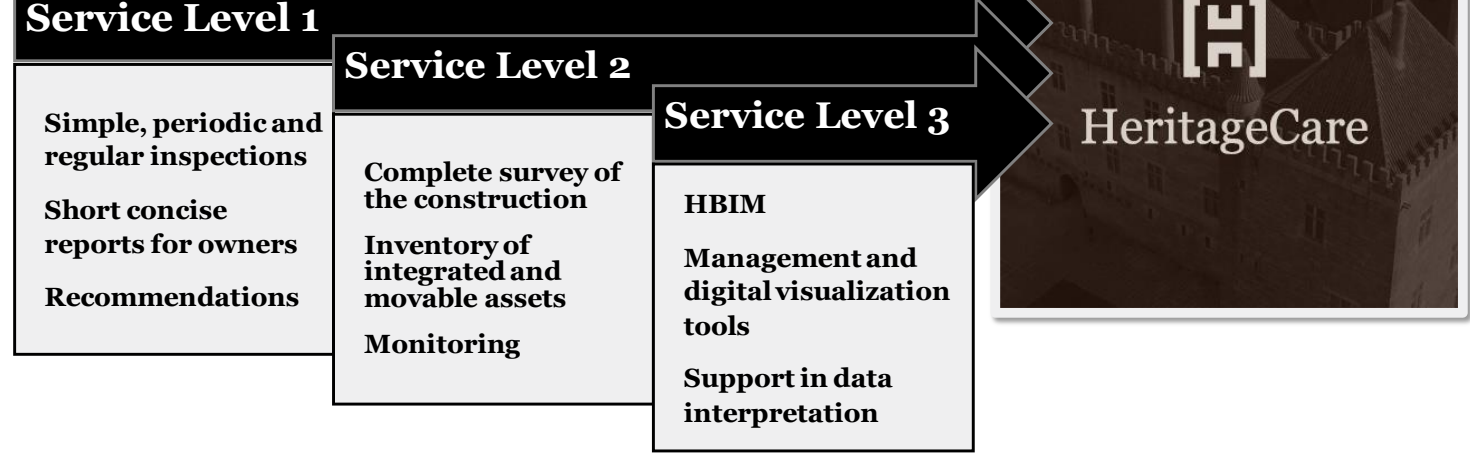

\begin{tabular}{lll}
\hline Service Level & Designation & Functionality \\
\hline SL1 & StandardCare & $\begin{array}{l}\text { Provision of what is essential for the primary health and } \\
\text { ordinary maintenance of the heritage building } \\
\text { Provision of what is necessary for the primary health, } \\
\text { ordinary maintenance and thorough screening of the } \\
\text { heritage building along with its integrated and movable } \\
\text { assets, including monitoring data to support decision } \\
\text { making }\end{array}$ \\
& PlusCare & $\begin{array}{l}\text { Provision of what is necessary for the primary health, } \\
\text { ordinary maintenance, thorough screening and enhanced } \\
\text { management of the heritage building along with its } \\
\text { integrated and movable assets }\end{array}$ \\
\hline
\end{tabular}

Figure 4. The HeritageCare multi-level system for preventive conservation. 
“This paper can be found at https://doi.org/10.1080/15583058.2019.1668985"

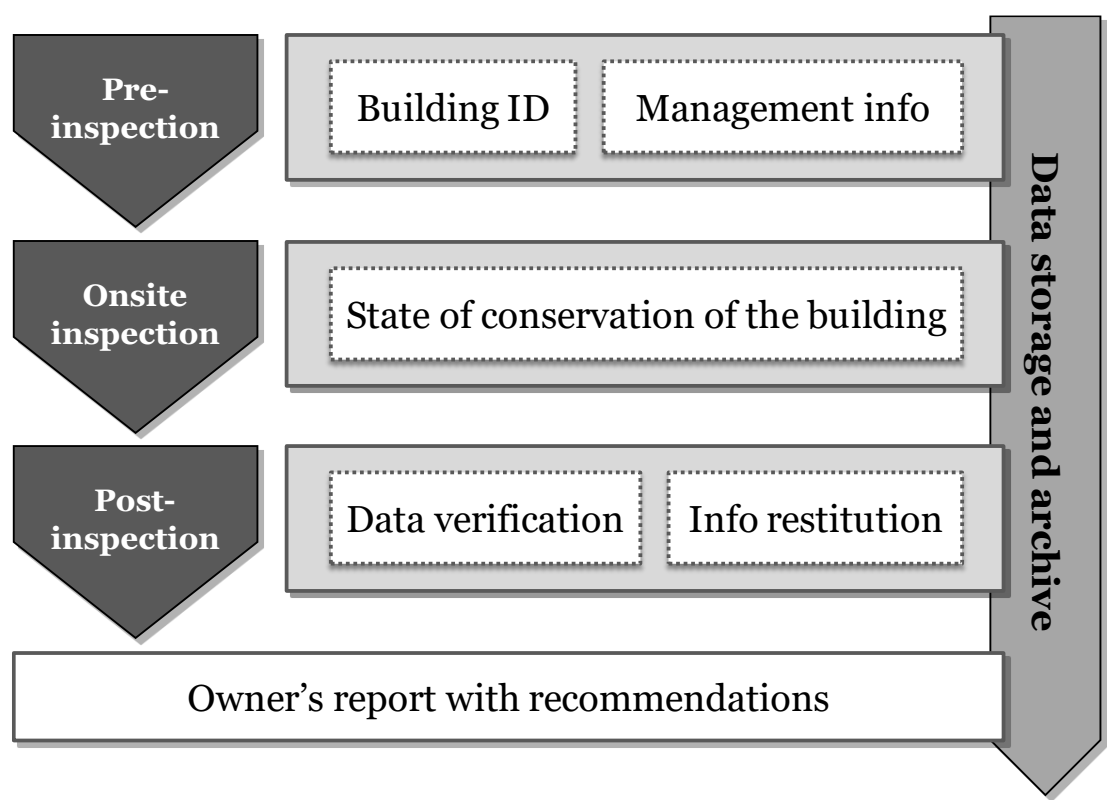

Figure 5. HeritageCare protocol for Service Level 1 (StandardCare). 


\begin{tabular}{|l|}
\hline 1. Roof covering \\
\hline 2. Roof supporting structure \\
\hline 3. Rain water system \\
\hline 4. Building envelope \\
\hline 5. Building interior \\
\hline 6. Integrated \& movable objects \\
\hline 7. Technical installations \& equipment \\
\hline 8. Indoor climate \\
\hline 9. Prevention and safety \\
\hline 10. Accessibility and hygiene \\
\hline 11. Site \\
\hline
\end{tabular}

3. Rain water system

3.1 Gutters

3.2 Rain pipes

3.3 Sewerage

3.4 Others

\section{Building interior}

5.1 Vertical structural elements

5.2 Horizontal structural elements

5.3 Internal finishing materials

5.4 Internal staircases and walkways

5.5 Doors and windows, including glasses

5.6 Others

(a)

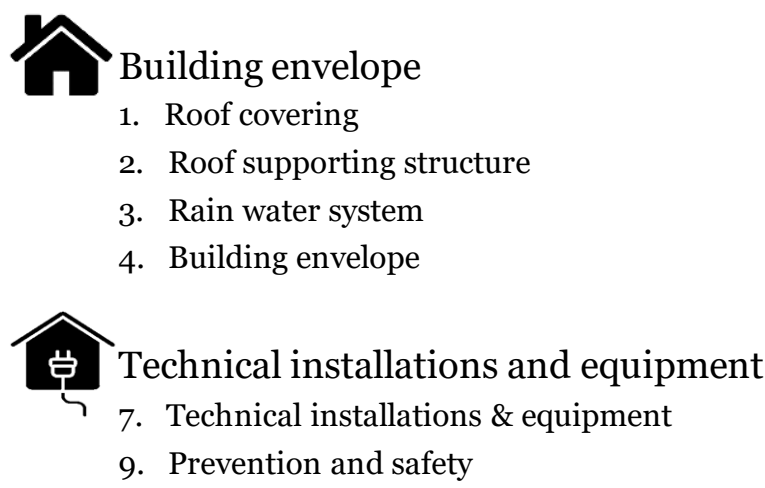

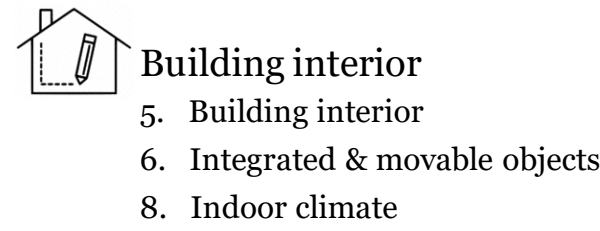

(1) Accessibility and hygiene 10. Accessibility and hygiene 11. Site

(b)

Figure 6. Inspection checklist: (a) list of items to inspect (only two lists of sub-items are shown as an example); (b) macro-categories of items. 
"This paper can be found at https://doi.org/10.1080/15583058.2019.1668985"

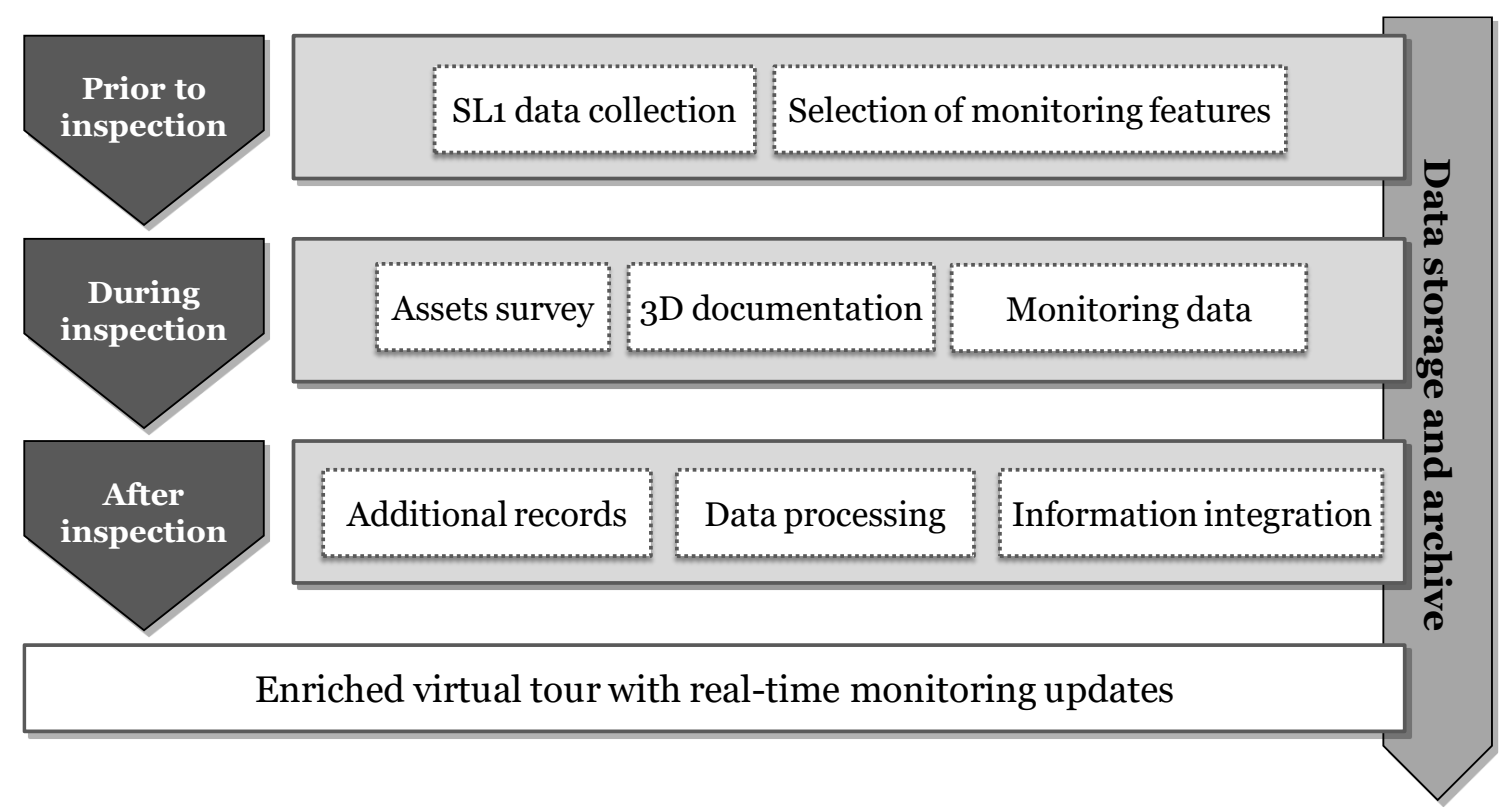

Figure 7. HeritageCare protocol for Service Level 2 (PlusCare). 
“This paper can be found at https://doi.org/10.1080/15583058.2019.1668985"

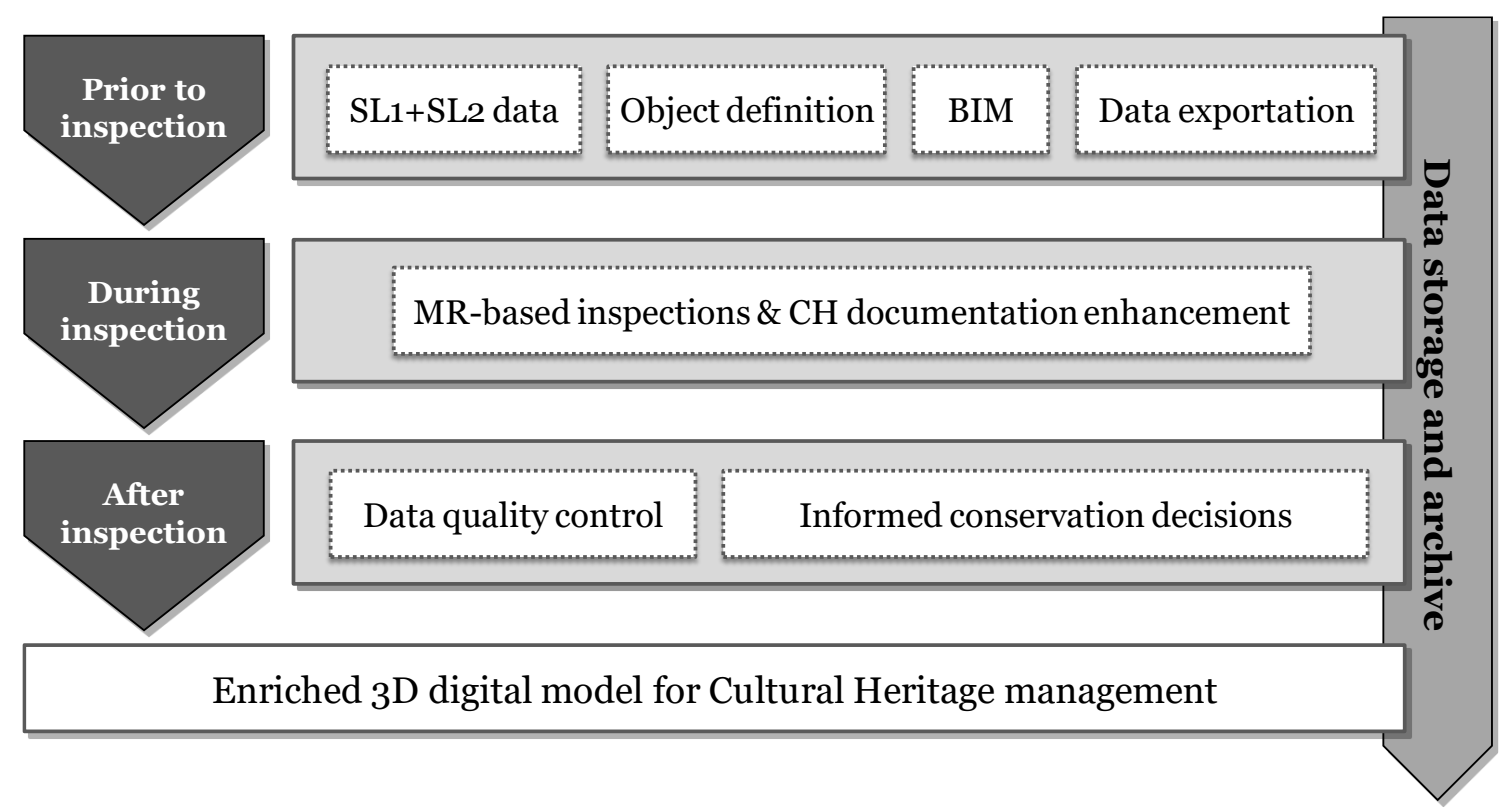

Figure 8. HeritageCare protocol for Service Level 3 (TotalCare). 
“This paper can be found at https://doi.org/10.1080/15583058.2019.1668985"

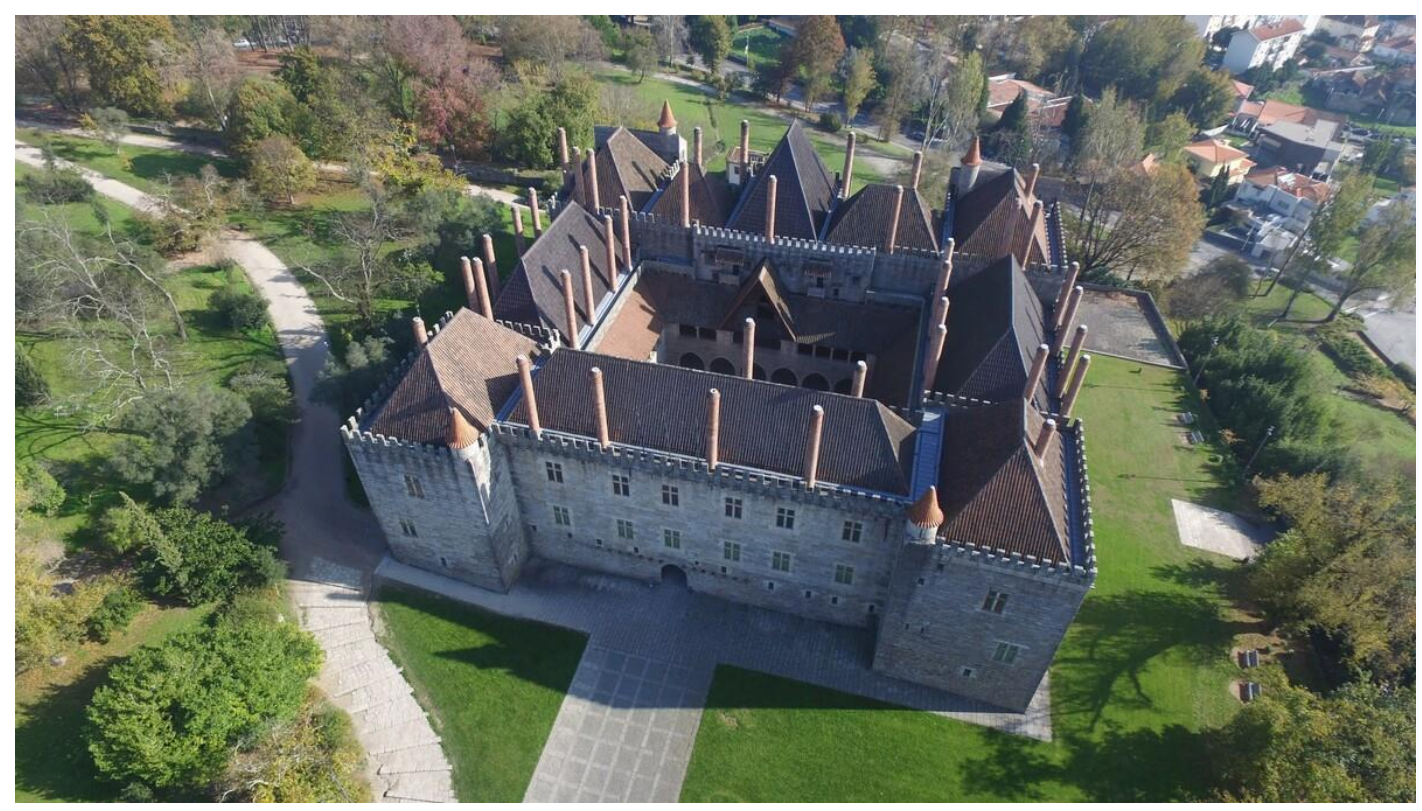

Figure 9. Bird's eye view of the Ducal Palace of Guimarães, Portugal. 
"This paper can be found at https://doi.org/10.1080/15583058.2019.1668985"

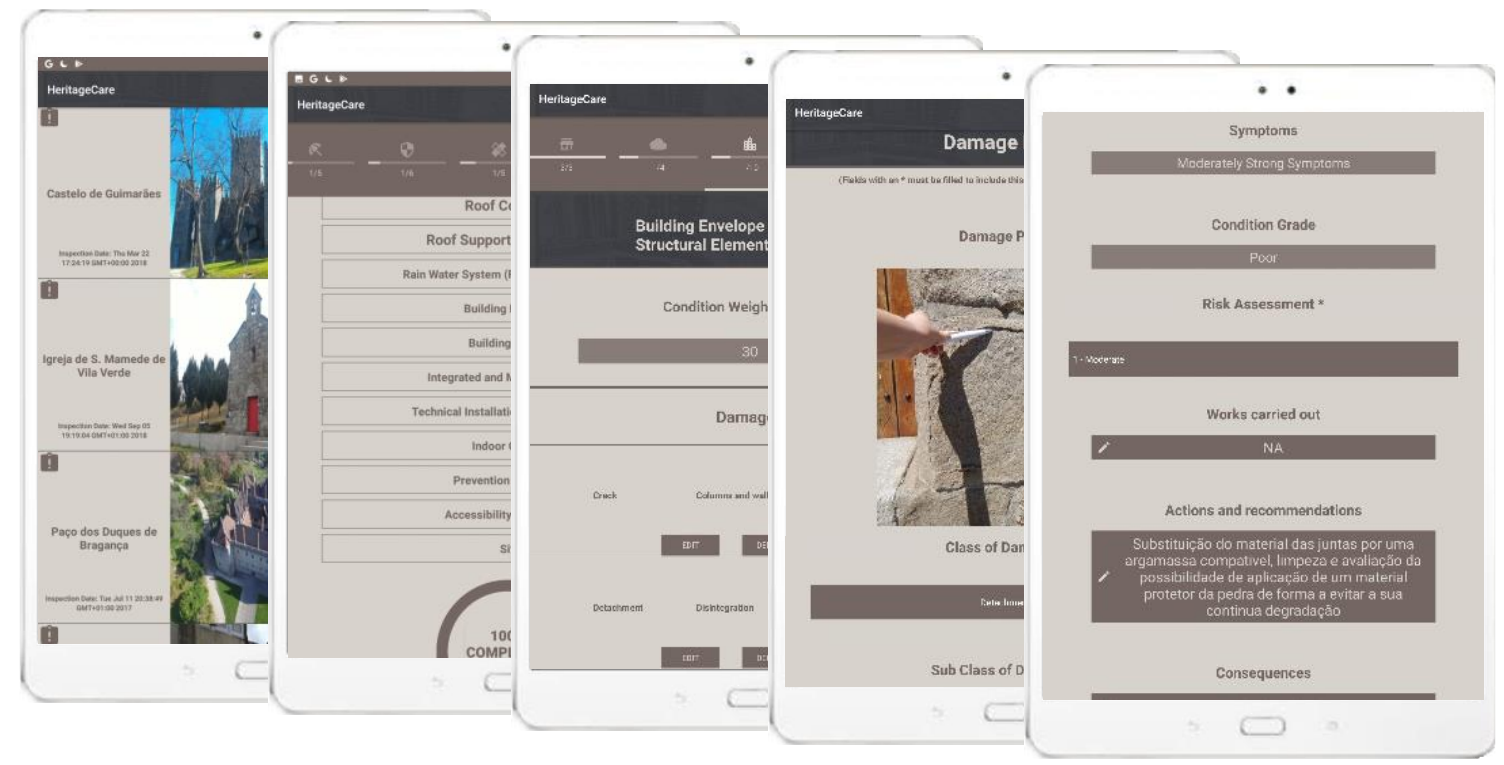

Figure 10. HeritageCare mobile app used for onsite inspection of the Ducal Palace. 
“This paper can be found at https://doi.org/10.1080/15583058.2019.1668985"
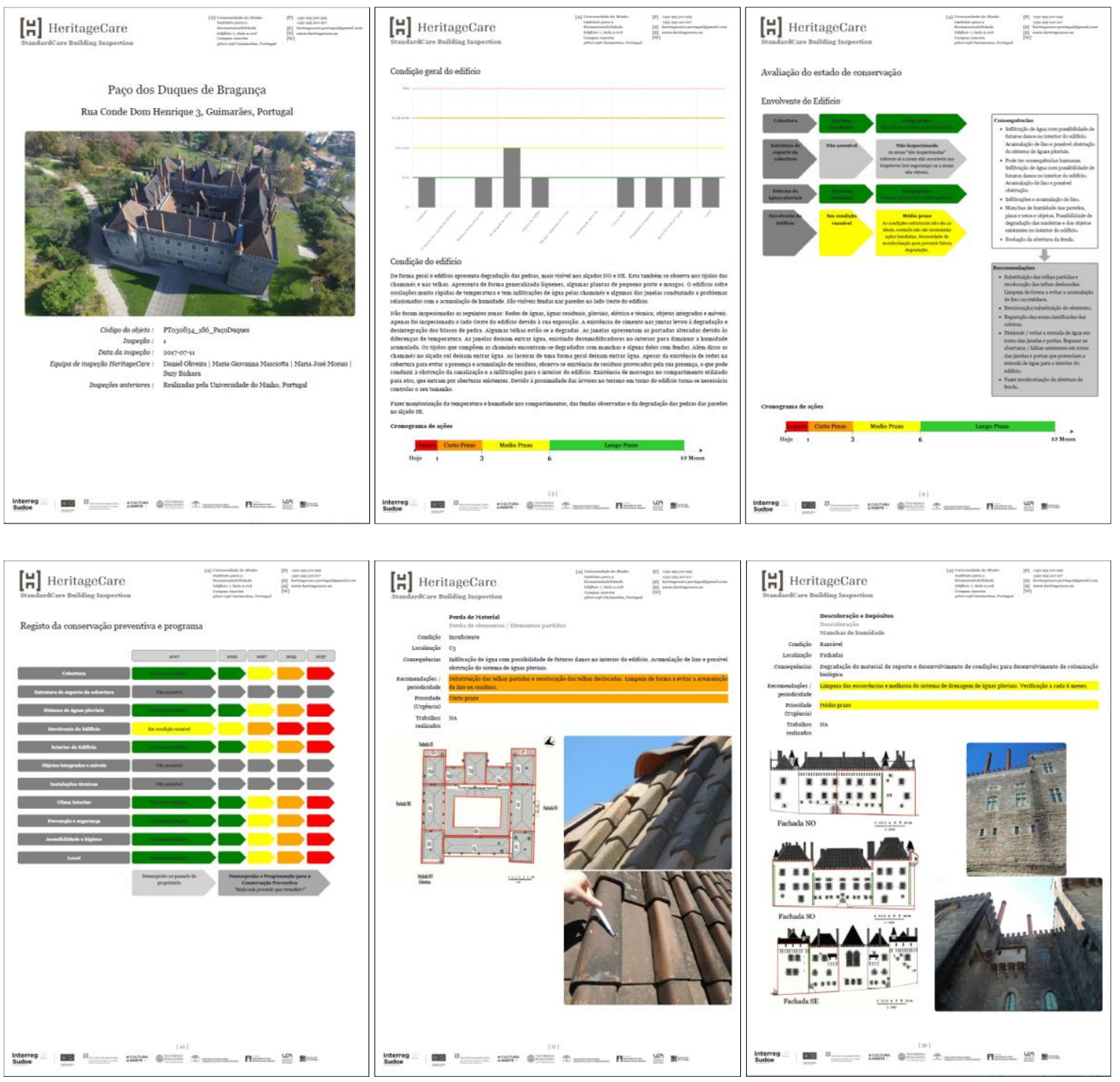

Figure 11. Excerpt from the StandardCare inspection report. 
"This paper can be found at https://doi.org/10.1080/15583058.2019.1668985"

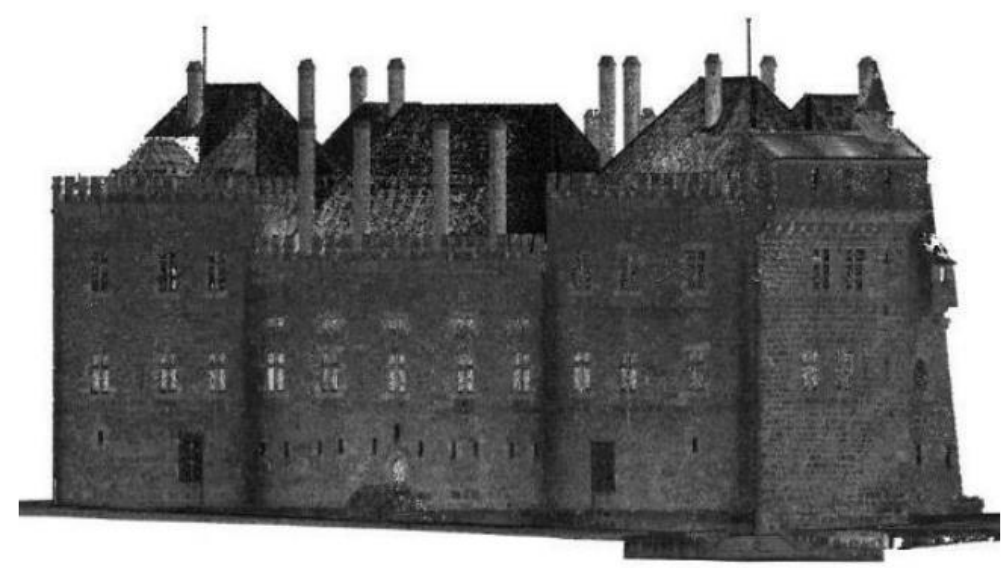

(a)

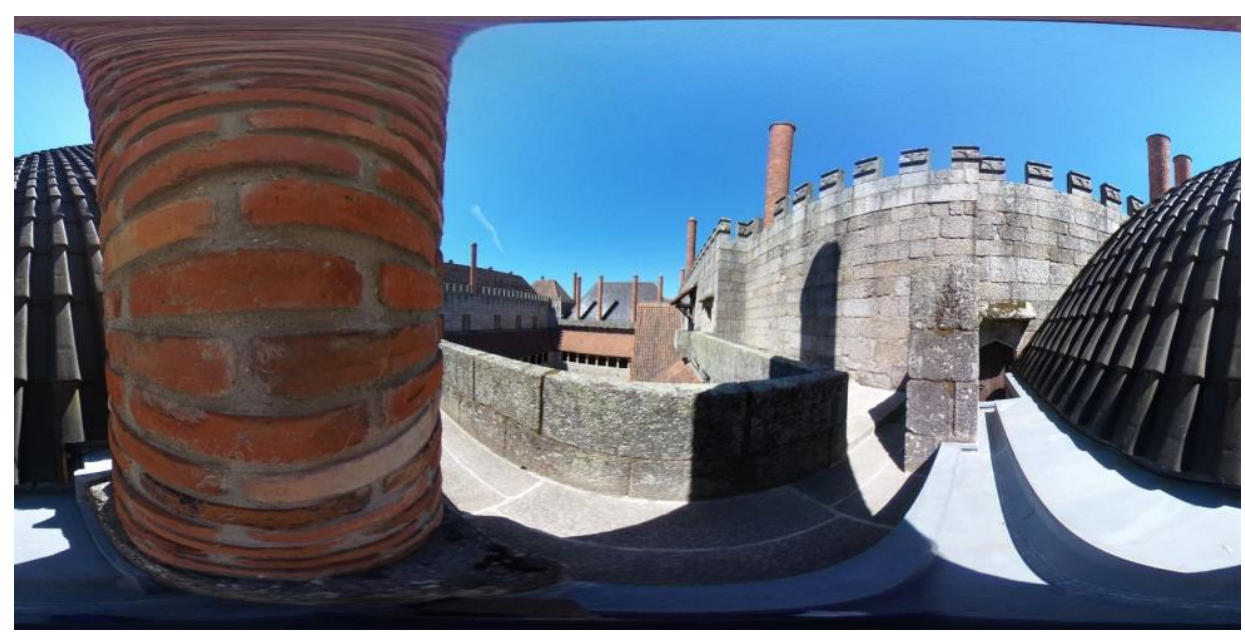

(b)

Figure 12. Geomatic products required for the PlusCare system: (a) high-resolution point cloud; and (b) spherical panorama. 
"This paper can be found at https://doi.org/10.1080/15583058.2019.1668985"
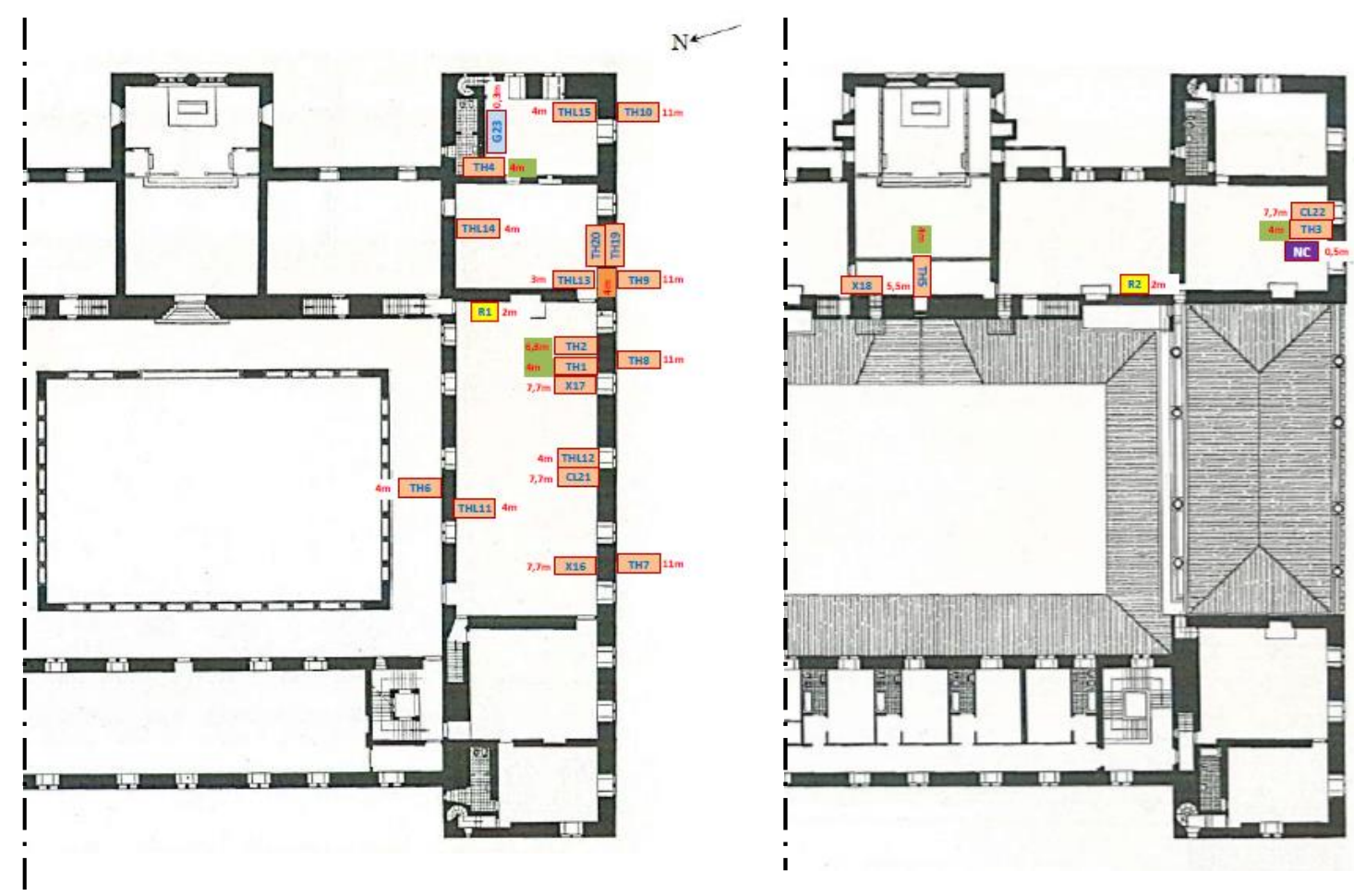

Figure 13. Sensor layout of the advanced monitoring system installed in the Ducal Palace. 
"This paper can be found at https://doi.org/10.1080/15583058.2019.1668985"

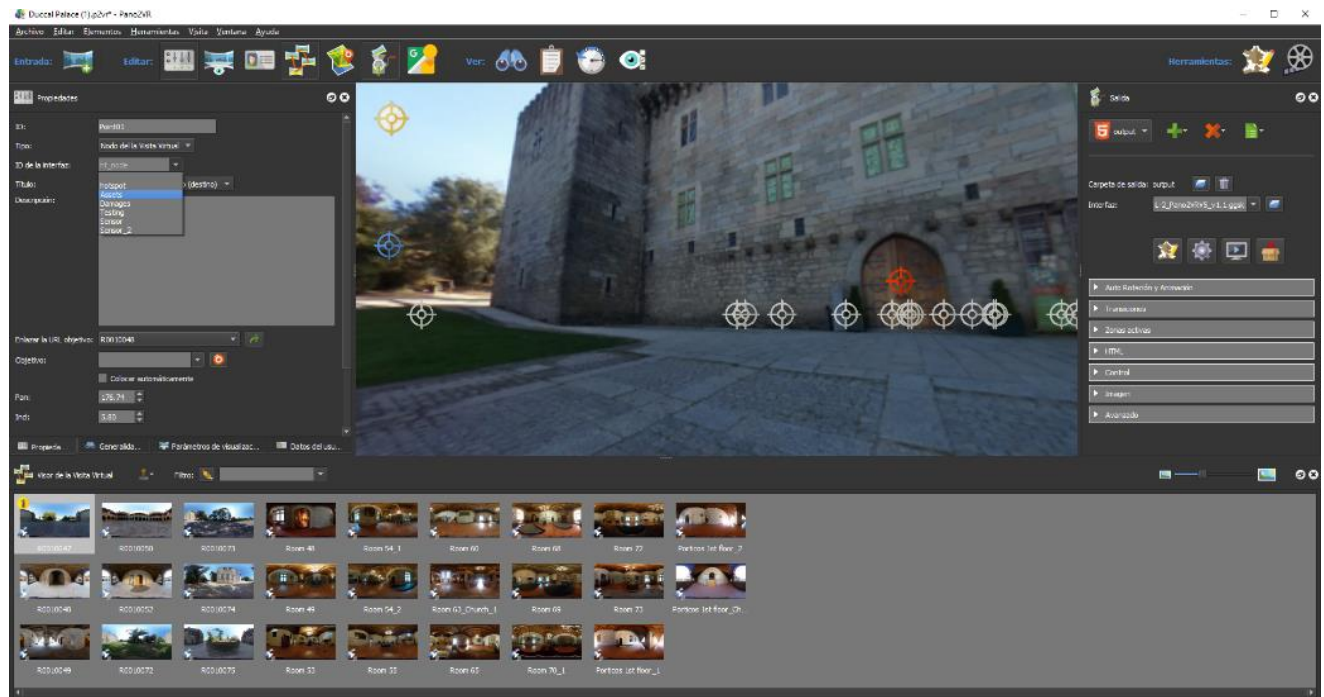

(a)

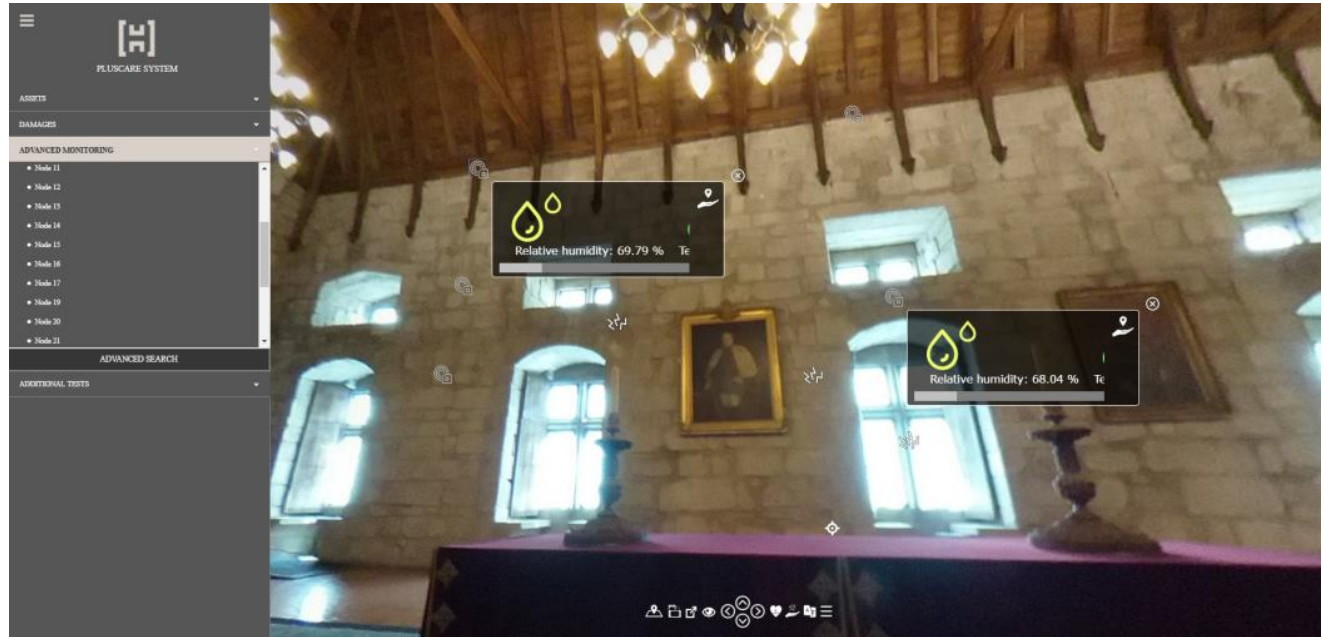

(b)

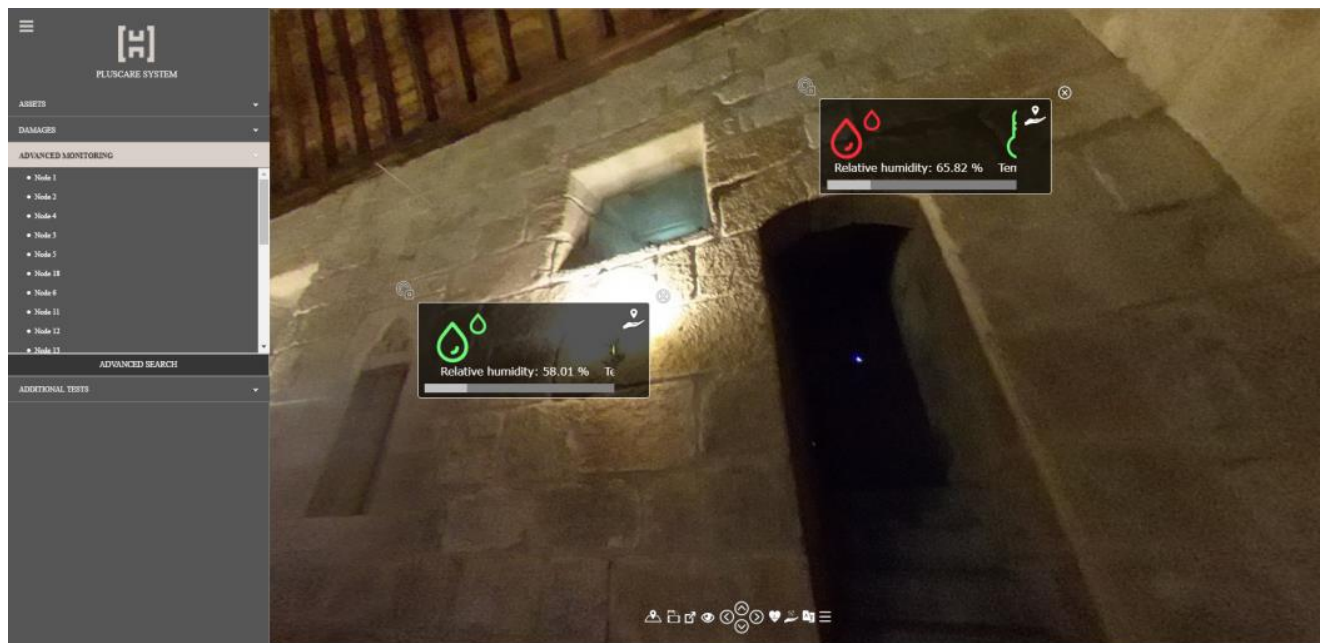

(c)

Figure 14. PlusCare system: (a) integration of information through the HeritageCare plugin for Pano2VR; (b) and (c) excerpts from the virtual tour of the Ducal Palace with display of monitoring data in real time. 
"This paper can be found at https://doi.org/10.1080/15583058.2019.1668985"

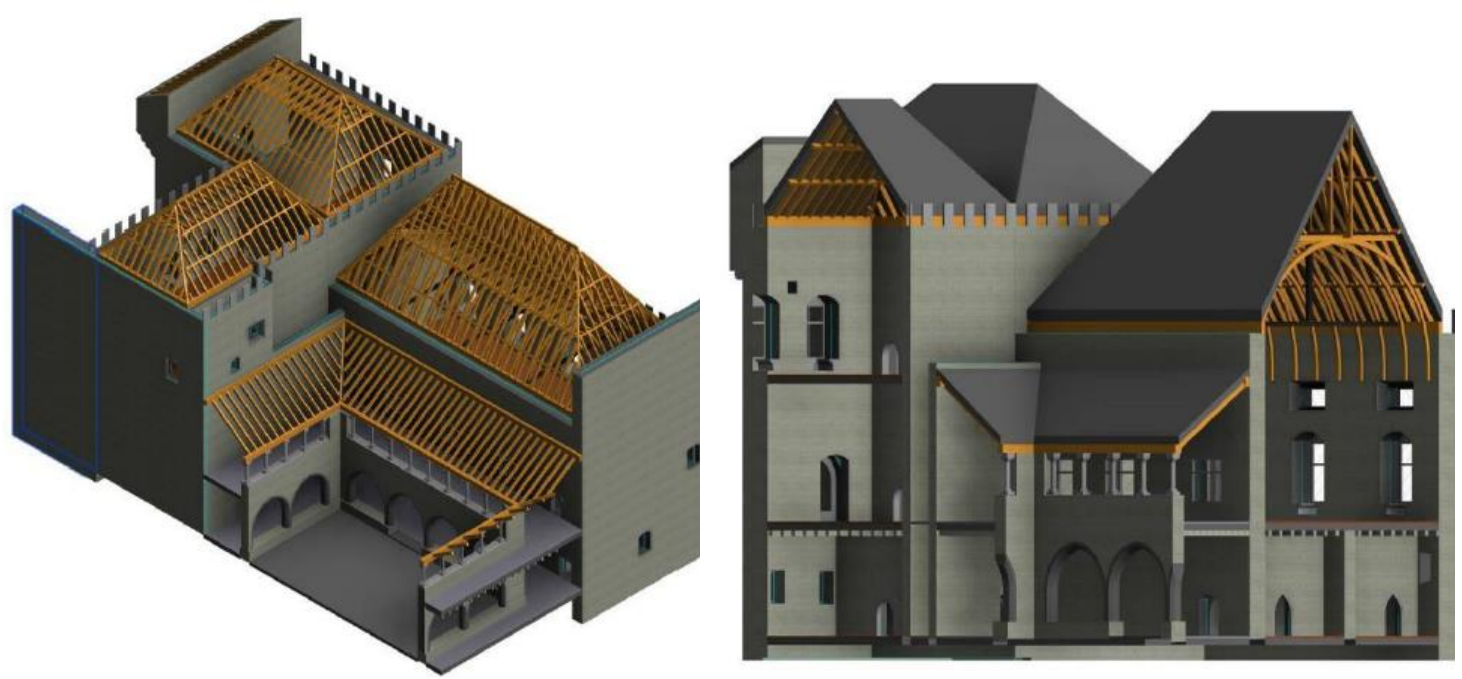

Figure 15. Views of the Ducal Palace BIM model (Alarcón, 2018). 
“This paper can be found at https://doi.org/10.1080/15583058.2019.1668985"

Table 1. HeritageCare damage rating system for condition and risk classification.

\begin{tabular}{|c|c|c|c|c|}
\hline $\begin{array}{l}\text { Class } \\
\text { No. }\end{array}$ & $\begin{array}{l}\text { Condition } \\
\text { Classification }\end{array}$ & Symptoms & $\begin{array}{l}\text { Urgency Risk } \\
\text { Classification }\end{array}$ & Comments \\
\hline o & Good & $\begin{array}{l}\text { No } \\
\text { symptoms }\end{array}$ & Long term & $\begin{array}{l}\text { No immediate actions required | Preventive } \\
\text { monitoring is necessary }\end{array}$ \\
\hline 1 & Fair & $\begin{array}{l}\text { Minor } \\
\text { Symptoms }\end{array}$ & Medium term & $\begin{array}{l}\text { The condition of the fabric is not perfect but } \\
\text { does not need immediate action | } \\
\text { Monitoring is necessary to prevent further } \\
\text { decay }\end{array}$ \\
\hline 2 & Poor & $\begin{array}{l}\text { Moderately } \\
\text { Strong } \\
\text { Symptoms }\end{array}$ & Short term & $\begin{array}{l}\text { The condition of the fabric is such that it } \\
\text { needs timely repair or additional inspection } \\
\text { and diagnosis work }\end{array}$ \\
\hline 3 & $\mathrm{Bad}$ & $\begin{array}{l}\text { Major } \\
\text { Symptoms }\end{array}$ & $\begin{array}{l}\text { Urgent and } \\
\text { Immediate }\end{array}$ & $\begin{array}{l}\text { Urgent repair is necessary |Urgent } \\
\text { additional inspection and diagnosis work }\end{array}$ \\
\hline $\mathrm{NA} / \mathrm{NI}$ & Not Accessible & $\begin{array}{l}\text { Parts not } \\
\text { (safely) } \\
\text { accessible }\end{array}$ & Not Inspected & $\begin{array}{l}\text { Parts that are 'not inspected' are either not } \\
\text { (safely) accessible for the building } \\
\text { inspectors or not visible }\end{array}$ \\
\hline
\end{tabular}


“This paper can be found at https://doi.org/10.1080/15583058.2019.1668985"

Table 2. Excerpt from data template structure for HBIM objects (Alarcón, 2018).

\begin{tabular}{|c|c|c|c|}
\hline Template name (for) & Historic Masonry Wall & & \\
\hline Suitability for Use & Asset Management & & \\
\hline Template Custodian & HeritageCare & & \\
\hline Parameter Name & Value & Units & Notes \\
\hline \multicolumn{4}{|l|}{$\begin{array}{l}\text { Masonry Wall } \\
\text { Construction Data }\end{array}$} \\
\hline Construction Date & & Years & Example: 1500 \\
\hline $\begin{array}{l}\text { Construction Date } \\
\text { Degree of Accuracy }\end{array}$ & & 0 to 5 & $\begin{array}{l}0=\text { rough estimation } \\
\text { without support. } \\
5=\text { Totally Sure. } \\
\text { Evamnla. ? }\end{array}$ \\
\hline Previous Intervention Dates & & Years & $\begin{array}{l}\text { Example: } 1590,1650,1900 \text {, } \\
2015\end{array}$ \\
\hline $\begin{array}{l}\text { Intervention Dates } \\
\text { Degree of Accuracy }\end{array}$ & & 0 to 5 & $\begin{array}{l}0=\text { rough estimation } \\
\text { without support. } \\
\text { 5=Totally Sure. } \\
\text { Example: } 0,5,4,5\end{array}$ \\
\hline \multicolumn{4}{|l|}{ Inspection Data } \\
\hline Inspection Dates & & Date & $\begin{array}{l}\text { Example: 1985/07, } \\
\text { 1994/05, 2010/05/ }\end{array}$ \\
\hline Last Inspection reference & & & $\begin{array}{l}\text { Name, address or any } \\
\text { other reference to track the } \\
\text { source. }\end{array}$ \\
\hline Brief Description & & & $\begin{array}{l}\text { General description of } \\
\text { last inspection }\end{array}$ \\
\hline Survey Picture URL & & & \\
\hline Geometric Data & & & \\
\hline
\end{tabular}

\begin{tabular}{lll}
\hline Thickness & $\mathrm{m}$ & Example: 1.25 \\
Height & $\mathrm{m}$ & Example: 2.55 \\
Length & $\mathrm{m}$ & Example: 15.23
\end{tabular}


Table 3. 3D recording strategies for different cultural heritage objects.

\begin{tabular}{|c|c|c|c|c|c|c|c|}
\hline \multirow{4}{*}{ Method } & \multicolumn{7}{|c|}{ Cultural Heritage objects } \\
\hline & \multirow{3}{*}{$\begin{array}{l}\text { Large } \\
\text { heritage } \\
\text { areas }\end{array}$} & \multirow[b]{3}{*}{ Outdoor } & \multicolumn{2}{|l|}{ Buildings } & \multicolumn{2}{|c|}{ Movable assets } & \multirow{3}{*}{$\begin{array}{c}\text { Underwater } \\
\text { heritage }\end{array}$} \\
\hline & & & \multicolumn{2}{|c|}{ Indoor } & \multirow{2}{*}{$\begin{array}{l}\text { Large- } \\
\text { medium } \\
\text { scale } \\
\text { assets }\end{array}$} & \multirow{2}{*}{$\begin{array}{l}\text { Small- } \\
\text { scale } \\
\text { assets }\end{array}$} & \\
\hline & & & $\begin{array}{l}\text { Spacious } \\
\text { areas }\end{array}$ & $\begin{array}{l}\text { Narrow } \\
\text { areas }\end{array}$ & & & \\
\hline $\begin{array}{l}\text { Close-range } \\
\text { terrestrial } \\
\text { photogrammetry }\end{array}$ & $\bullet$ & $\bullet \bullet$ & $\bullet$ & $\bullet$ & $\bullet$ & $\bullet$ & $\bullet$ \\
\hline $\begin{array}{l}\text { Close-range } \\
\text { aerial } \\
\text { photogrammetry }\end{array}$ & $\bullet$ & $\bullet$ & $\bullet$ & + & $\ddagger$ & $\ddagger$ & $\ddagger$ \\
\hline $\begin{array}{l}\text { Static laser } \\
\text { scanner }\end{array}$ & $\bullet$ & $\bullet$ & $\bullet$ & - & $\bullet$ & $\bullet$ & $\bullet * *$ \\
\hline $\begin{array}{l}\text { Back-pack } \\
\text { mapping }\end{array}$ & $\bullet \bullet$ & - & $\bullet$ & $\bullet \bullet$ & $\bullet$ & $\bullet$ & + \\
\hline
\end{tabular}

Scoring legend: $\quad$ •• Highly recommended $\quad$ • Can be used $\quad$ •** Can be used but requires the extraction of the piece - Not recommended $\$$ cannot be used. 
“This paper can be found at https://doi.org/10.1080/15583058.2019.1668985"

Table 4. Examples of virtual representation of the elements surveyed in the Palace (Alarcón, 2018).

\begin{tabular}{ccc}
\hline Name & Survey photo & Virtual representation \\
\hline $\begin{array}{c}\text { Concrete slab } \\
\text { + brick floor }\end{array}$ \\
Column \\
$\begin{array}{c}\text { Double stone arch } \\
\text { wood door }\end{array}$
\end{tabular}

